Exemplaria Classica

Journal of Classical Philology

$22,2018,65-90$

ISSN 1699-3225

\title{
UNA PROPUESTA DE ESTUDIO DEL LÉXICO SEXUAL GRIEGO:
} LOS TEXTOS ASTROLÓGICOS

\author{
Juan Francisco Martos Montiel \\ Universidad de Málaga \\ jfmartos@uma.es
}

\begin{abstract}
SUMMARY
A status quaestionis of the study of Greek sexual vocabulary is offered, proposing a global approach that includes texts in which few efforts have been made in that sense, such as astrological texts, whose importance for this semantic field is underlined and analyzed by several examples.
\end{abstract}

KEY WORDS

Greek sexual vocabulary; astrological texts.

\section{RESUMEN}

Se presenta un status quaestionis del estudio del léxico erótico, sexual y obsceno de la lengua griega y se propone un enfoque global que incluya textos poco trabajados en ese sentido como son los astrológicos, de cuya importancia para dicho campo semántico se ofrecen y discuten diversos ejemplos.

Palabras Clave

Léxico erótico griego; textos astrológicos.

Fecha de recepción: 7/06/2018

Fecha de aceptación y versión final: 17/09/2018

[T] he attempt to reconstruct social attitudes from the terminology used to convey them is often hazardous, complex, and controversial. However, precisely because vocabulary carries some of the complexity of our thinking, it is a subject worthy of exploration and a pathway to a more profound understanding of the conceptual labyrinth that normally accompanies our social structures, values, and interactions. ${ }^{1}$

${ }^{1}$ K.A. Kapparis, "The Terminology of Prostitution in the Ancient Greek World", en A. Glazebrook, M. Henry, eds., Greek prostitutes in the ancient Mediterranean, Madison 2011, 222-55, en p. 222.

BIBLID [1699-3225 (2018) 22, 65-90] 
1. El ESTUDIO DEL LÉXICO ERÓTICO Y SEXUAL GRIEGO: STATUS QUAESTIONIS.

Como es sabido, el estudio de las costumbres sexuales de la Antigüedad clásica solo pudo enfrentarse en época moderna con la debida libertad y sin las habituales restricciones pudoris causa a partir de los años sesenta y setenta del pasado siglo, superada ya la tradicional "censura erótica de carácter eufemístico" 2 a la que se vio sometida secularmente tanto la transmisión, primero, como después la edición y traducción de los textos clásicos y que, con escasas excepciones, impedía imprimir palabras consideradas obscenas o escribir libremente sobre sexualidad sin recurrir a "la decente oscuridad de un lenguaje culto", por usar la famosa frase atribuida al historiador Edward Gibbon.

En este sentido, los estudiosos han prestado especial atención en las últimas décadas al vocabulario erótico-sexual-obsceno de las lenguas griega y latina, tratando de delimitar y sistematizar este campo léxico, profundizar en las claves de su formación (metáfora, eufemismo, doble sentido, etc.) y analizar su función en los géneros literarios. En esta tarea tuvo un importante papel la labor del filólogo alemán Werner Krenkel, quien entre 1965 y 1990 publicó numerosos artículos sobre los hábitos sexuales de griegos y romanos ${ }^{3}$ en los que, además de recoger y comentar con rigor muchísimos testimonios, dedicaba buena parte de su metódico trabajo a la catalogación, definición y usos de las palabras y expresiones relevantes para cada tema tratado, pero destaca sobre todo la llamada "escuela de Manchester", integrada por filólogos de la talla de Henri David Jocelyn, David Bain y James Noel Adams, quienes desde finales de los setenta dedicaron sus esfuerzos específicamente al estudio y discusión de los términos utilizados por las lenguas griega y latina para referirse a los órganos genitales y sus funciones y, en general, al análisis de las expresiones relacionadas en estas lenguas con la sexualidad y la obscenidad y su valoración interna según criterios morales, religiosos y estéticos. Fruto de este interés fueron una larga serie de trabajos entre los que sobresale sin duda

${ }^{2}$ Tomamos la expresión de E. Montero Cartelle, "Censura y transmisión textual en Marcial", EClás. 78, 1976, 343-52, en p. 344. Sobre la censura en las traducciones de los textos grecolatinos véase especialmente K.J. Dover, "Expurgation of Greek Literature”, en Les Études Classiques aux XIXe et XXe siècles: leur place dans l'histoire des idées, Ginebra 1980, 5589 , y, por lo que respecta a nuestro país, M. González González, "La censura en las traducciones de los clásicos griegos. El ejemplo de Platón y Aristófanes”, Faventia 29.1, 2007, 77-88, y J. Fernández Valverde, "Casto expurgo hispano de Marcial”, en R. Moreno Soldevila, J. Martos, eds., Amor y sexo en la literatura latina, Huelva 2014, 181-96.

${ }^{3}$ La lista de temas estudiados por Krenkel es amplísima: masturbación, sexo oral, tribadismo, pederastia, travestismo, exhibicionismo, escopofilia, aborto, pornografía, etc. En nuestra Bibliotheca Erotica Graeca et Latina (una extensa bibliografía analítica en acceso libre online: https://sites.google.com/site/proyectoaevum/) se encontrará un listado exhaustivo de sus artículos, la mayoría de los cuales fueron recogidos en W. Krenkel, Naturalia non turpia. Sex and Gender in Ancient Greece and Rome. Schriften zur antiken Kultur- und Sexualwissenschaft. Herausgegeben von Wolfgang Bernard und Christiane Reitz (Spudasmata, 113), Hildesheim 2006. 
la monografía de $\mathrm{Adams}^{4}$ sobre el vocabulario sexual latino, un libro rico y riguroso, que trata de manera sistemática los testimonios de las fuentes, tanto literarias como no literarias, hasta en torno al siglo VII, aunque sin olvidar importante material medieval, y que, a pesar de algunas críticas fundadas que recibió en su momento y otras que aún hoy pueden hacérsele en puntos concretos, como veremos más adelante, pronto se convirtió en una obra de referencia ${ }^{5}$.

Pero no ocurre así, por desgracia, en el caso del vocabulario sexual griego, para el que carecemos de una obra de referencia similar a la de Adams, que trate el tema de forma exhaustiva, por más que podamos encontrar, como veremos a continuación, útiles recopilaciones de materiales, numerosos estudios parciales sobre su utilización en determinados géneros literarios o en tales o cuales autores y valiosos comentarios a obras o a pasajes concretos de especial relevancia para la cuestión.

Entre los trabajos más antiguos merece citarse en primer lugar, y no solo por obvias razones cronológicas, el benemérito De figuris Veneris de Friedrich Karl Forberg ${ }^{6}$, una culta disertación que ofrece un extenso repertorio

4 J.N. Adams, The Latin Sexual Vocabulary, Londres 1982. El prefacio de Jocelyn a la traducción italiana de este libro (a cargo de M.L. Riccio Coletti, E. Riccio, Il vocabolario del sesso a Roma, Lecce 1996, 13-16) lista los principales trabajos de la "Escuela de Manchester" hasta mediados de la década de los noventa; vid. también J.N. Adams, "Henry David Jocelyn, 1933-2000", PBA 120, 2003, 277-99, y [A. Coker, "Bibliography of David Bain's works on Aischrologia"], Eikasmos 25, 2014, 415-16.

5 Para la diversa valoración de la obra de Adams véase, por ejemplo, la dura crítica de E. Montero Cartelle en Emerita 73, 1985, 370-2, que resalta errores metodológicos de base y desconocimiento o no utilización de importantes obras anteriores sobre el tema, frente al elogioso juicio de J. André, Le vocabulaire latin de l'anatomie, París 1991, 160 n. 73, pocos años después: "un ouvrage capital par sa richesse, sa rigueur et sa valeur scientifique, et qui fait date". Sobre vocabulario obsceno latino cabe citar también la obra de A. Richlin, The Garden of Priapus. Sexuality and Agression in Roman Humor, New Haven - Londres 1983, poco posterior a la de Adams pero bastante menos recomendable a la vista de sus discutibles afirmaciones, rechazables traducciones y no pocos errores, señalados por H.D. Jocelyn, "Concerning an American view of Latin sexual humour", $E M C$ 4, 1985, 1-30, en una reseña tan larga como ácida y solo en parte corregidos en la edición revisada de 1992 (que ignora, por cierto, la citada reseña de Jocelyn).

${ }^{6}$ Como es sabido, la obra de Forberg apareció como apéndice a su edición de la colección de epigramas eróticos latinos publicada hacia 1425 por el italiano Antonio Beccadelli, el Panormita (Antonii Panormitae Hermaphroditus. Primus in Germania edidit et apophoreta adjecit Frider. Carol. Forbergius, Coburgo 1824). Este apéndice o apophoreta, que ocupaba de la página 205 a la 383 y aparecía titulado De figuris Veneris, se tradujo primero al francés con el nombre, que luego haría fortuna, de Manuel d'érotologie classique, París 1882 y poco después al inglés (Manual of Classical Erotology, 2 vols., Manchester 1884; reimpr. Nueva York 1966). A comienzos del siglo XX, la obra completa sería traducida al alemán (Leipzig 1908) y dos décadas después al italiano, de nuevo solamente el apéndice (Manuale di erotologia classica, Catania 1928). En España, sin embargo, hemos tenido que esperar casi dos siglos para tener una edición (mala) y traducción castellana (pésima) de esta obra (De figuris Veneris. Manual de erótica clásica, Madrid 2007): vid. nuestra crítica en J.F. Martos Montiel, “«Sobre 
de testimonios literarios de las diversas prácticas sexuales del mundo grecolatino, comentados por lo general con notable pericia filológica (no exenta, sin embargo, de algunos errores), que le sirven para catalogar y explicar numerosos vocablos y expresiones de significado obsceno. Habría que esperar más de un siglo para contar con el Glossarium eroticum de Gaston Vorberg ${ }^{7}$, una especie de diccionario enciclopédico del lenguaje erótico griego y latino, profusamente ilustrado con escenas de arte erótico clásico, aunque con poca profundidad y demasiadas carencias en las explicaciones y ejemplos de muchas de sus entradas. Pocos años después se publicaría el primer trabajo sobre el tema dedicado exclusivamente a la lengua griega, los 'Aлó $\rho \rho \eta \alpha$ de Eúros

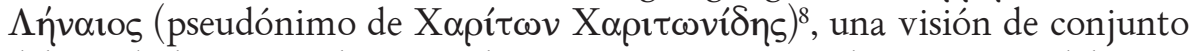
del vocabulario sexual y escatológico griego, organizado por partes del cuerpo y actos sexuales (y excretorios), que presta mucha atención a la historia y etimología de las palabras y a sus aspectos sociales (eufemismos, vulgarismos, etc.) y está filológicamente bien cuidada, aunque por lo general ha sido poco conocida y menos manejada en el campo de la Filología Clásica.

Tras el paréntesis que supuso el conflicto bélico mundial y la lenta recuperación de la posguerra, y animados por la apertura de mentes y la liberación de costumbres promovidas por distintos movimientos sociales durante los años sesenta y setenta del pasado siglo, en su último cuarto vieron la luz muchos trabajos sobre el tema que nos ocupa, algunos muy importantes y entre ellos dos especialmente destacables por su rigurosa utilización de las fuentes y su profundización en el estudio del léxico erótico y sexual griego: nos referimos al libro de Jeffrey Henderson sobre el lenguaje obsceno en la comedia ática y al de Kenneth James Dover sobre la homosexualidad griega.

las tríbadas»: una traducción anotada del capítulo VI del Manual de erotología clásica (De figuris Veneris) de F.-K. Forberg”, en R. Moreno Soldevila, J. Martos, eds., Amor y sexo en la literatura latina, Huelva 2014, 197-220, en pp. 199-201.

7 G. Vorberg, Glossarium eroticum, Stuttgart 1932 (reimpreso en Roma, por la editorial L'Erma di Bretschneider, y en Hanau, por Müller \& Kiepenheuer, ambas en 1965, pero con diferencias en las ilustraciones). En realidad esta obra, escrita, a pesar de su título, no en latín (como la disertación de Forberg) sino en alemán, fue publicada por entregas entre 1928 y 1932.

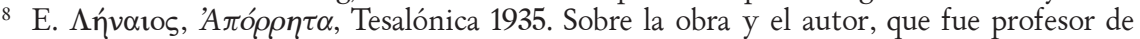

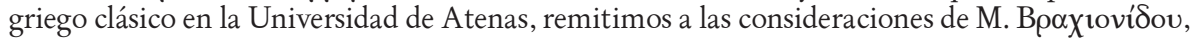

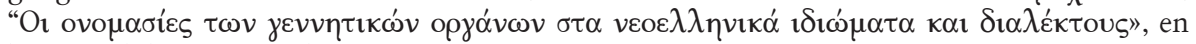
Z. Gavriilidou et al., eds., Selected papers of the 10th International Conference of Greek Linguistics, Komotiní 2012, 725-32, en p. 726. Si queremos ampliar el marco cronológico, la recopilación de materiales del librito de $\Lambda$ ńvolos puede completarse para el griego bizantino

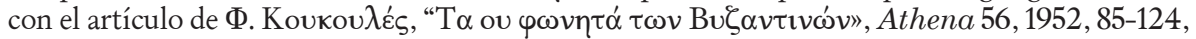

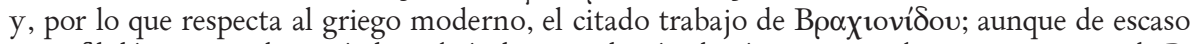
rigor filológico, puede ser útil también la recopilación de términos con breve comentario de $\mathrm{P}$.

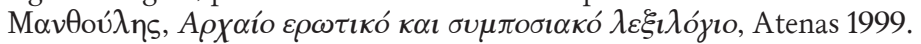


El de Henderson ${ }^{9}$, en efecto, es sin duda el principal estudio sobre el lenguaje obsceno de la comedia, pero no solo: buena parte del libro se ocupa de la obscenidad, tanto en general como en el desarrollo de la comedia ática y en concreto en la obra aristofánica, y trata también con cierto detalle los fragmentos de yambógrafos arcaicos, si bien su tratamiento del drama satírico y de la comedia nueva es breve e irregular. La segunda parte del libro es sin duda la más valiosa: un glosario de términos sexuales y escatológicos ordenados alfabéticamente y agrupados en parágrafos numerados bajo diversos epígrafes ("sexual organs", "sexual congress", "scatological humour", "homosexuality"), con unos valiosos índices finales (sobre todo el de palabras griegas). Aunque la segunda edición (1991) reproduce sin alteraciones el texto de la primera, el autor incluyó en ella un prefacio que repasa el desarrollo posterior del tema, amplió bastante la bibliografía y añadió treinta páginas de adenda, corrigenda, retractanda muy útiles.

Por su parte, el libro de Dover ${ }^{10}$ se basó también por extenso en las obras de Aristófanes y los fragmentos de otros autores de la comedia ática, junto con otras fuentes literarias (discursos de oradores como Esquines o Demóstenes, escritos filosóficos de Jenofonte, Platón o Aristóteles, poesía helenística, etc.) y arqueológicas (sobre todo pintura vascular de época arcaica y clásica), para estudiar a fondo el léxico erótico y sexual griego, en particular el relacionado con la homosexualidad y la pederastia, y sus certeras reflexiones y comentarios sobre este, recogido igualmente en unos útiles indices, son aún de obligada consulta para los estudiosos de estos temas. De hecho, en la introducción a su libro sobre el vocabulario sexual latino, Adams prefirió remitir a Dover por lo que respecta al griego, antes que a Henderson, que le parecía "muy impreciso" ", aunque lo cierto es que desde los años noventa se suele considerar cada vez más este último como la obra de referencia en el campo de la aischrología griega.

En cualquier caso, no es menos cierto que, junto a estas dos relevantes monografías, y sin olvidar algunos de los artículos de Krenkel mencionados anteriormente que se refieren tanto al ámbito griego como al latino ${ }^{12}$, han ido apareciendo en las últimas décadas una serie de trabajos importantes

9 J. Henderson, The Maculate Muse. Obscene Language in Attic Comedy, New Haven 1975 (manejamos, y consecuentemente citamos por, la $2^{\mathrm{a}}$ ed. revisada y ampliada, Nueva York - Oxford 1991).

10 K.J. Dover, Greek Homosexuality, Londres 1978 (manejamos, y consecuentemente citamos por, la $2^{\text {a }}$ ed., "updated and with a new Postscript", Cambridge, MA 1989; de esta edición existe una trad. española [a cargo de J.F. Martos Montiel, J.L. López Cruces, Barcelona 2008] que incluye correcciones y añadidos del autor y una actualización bibliográfica).

11 Adams, Latin Sexual Vocabulary, 1 n. 2.

${ }^{12}$ Vid. sobre todo W. Krenkel, "Masturbation in der Antike", WZRostock 28.3, 1979, 15978; "Fellatio and irrumatio", WZRostock 29.5, 1980, 77-88; "Tonguing", WZRostock 30.5, 1981, 37-54; "Figurae Veneris I", WZRostock 34.4, 1985, 50-7; "Figurae Veneris II", WZRostock 36.6, 1987, 49-56; "Tribaden”, WZRostock 38.5, 1989, 49-58. 
que estudian el lenguaje erótico, sexual y obsceno del griego desde distintas perspectivas, en autores o géneros determinados o centrándose en un campo semántico específico o incluso en un término concreto. Por limitarnos simplemente a entresacar algunos de los que nos parecen más destacables ${ }^{13}$, podemos citar la tesis de Siems sobre el lenguaje obsceno en el epigrama griego (y latino $)^{14} y$, por oposición, el más reciente artículo - póstumo- de Bain sobre la presencia de palabras malsonantes en la épica y otros géneros elevados ${ }^{15}$, que junto con el breve repaso de Henderson al -muy escaso- vocabulario indecoroso de la tragedia griega y del drama satírico ${ }^{16}$ (este algo más abundante, aunque normalmente se evitan las obscenidades primarias y se usan metáforas y eufemismos) pueden completar ahora el trabajo de Cassanello sobre la terminología erótica en el género trágico ${ }^{17}$, una aportación bastante original en su momento por tratarse de un aspecto poco estudiado de forma global hasta entonces. También debe citarse la importante recopilación y análisis de materiales sobre el eufemismo sexual y escatológico de De Martino \& Sommerstein $^{18}$, que estudia con profundidad el tema tanto en general como en la comedia y la historiografía y más por extenso en el género de la oratoria y en la medicina, campos en los que cabe recordar también los artículos de Opelt y de Mélèze-Modrzejewski sobre el lenguaje soez e injurioso en la oratoria y su tratamiento en el derecho griego ${ }^{19}$ o los útiles trabajos de Skoda y de Catonné sobre el vocabulario utilizado habitualmente por los médicos griegos para referirse al aparato genital masculino y femenino y sus afecciones y para aludir a las prácticas sexuales de los enfermos ${ }^{20}$. Debemos recordar igualmente los

\footnotetext{
${ }^{13}$ Para una relación más exhaustiva, remitimos al apartado sobre "Léxico erótico-sexual" de nuestra citada Bibliotheca Erotica Graeca et Latina.

14 Andreas K. Siems, Aischrologia. Das Sexuell-Häßliche im antiken Epigramm, Gotinga 1974.

${ }^{15}$ D. Bain $(\dagger)$, "Low Words in High Places: Sex, Bodily Functions, and Body Parts in Homeric Epic and Other Higher Genres", en P.J. Finglass, C. Collard, N.J. Richardson, eds., Hesperos. Studies in Ancient Greek Poetry Presented to M. L. West on his Seventieth Birthday, Oxford 2007, 40-57. Vid. también en general I.E. Holmberg, "Sex in Ancient Greek and Roman Epic", en Th.K. Hubbard, ed., A Companion to Greek and Roman Sexualities, Oxford 2014, 314-34.

${ }^{16}$ J. Henderson, "Obscene Language", en The Encyclopedia of Greek Tragedy, Wiley Online Library, 2012 <http://onlinelibrary.wiley.com/doi/10.1002/9781118351222.wbegt9993/ pdf>. Vid. también en general H.M. Roisman, "Sexuality in the Extant Greek and Roman Tragedies", en Hubbard, Companion to Greek and Roman sexualities, 352-65.

${ }^{17}$ M.T. Cassanello, Lessico erotico della tragedia greca, Roma 1993.

${ }^{18}$ F. De Martino, A.H. Sommerstein, eds., Studi sull'eufemismo, Bari 1999.

19 I. Opelt, "Schimpfwörter bei den attischen Rednern", Glotta 70, 1992, 226-38; J. Mélèze-Modrzejewski, “Paroles nefastes' et 'vers obscènes'. À propos de l'injure verbale en droit grec et hellénistique”, Dike 1, 1998, 151-69.

${ }^{20}$ F. Skoda, "Les appareils genitaux" y "Les affections de l'appareil genital", en su libro Médecine ancienne et métaphore. Le vocabulaire de l'anatomie et de la pathologie en grec ancien, París 1988, 156-84 y 295-300; J.-Ph. Catonné, "Étude du vocabulaire sexuel hippocratique”, $B A G B$ 6, 1993, 332-49. Sobre los genitales, tanto en el ámbito médico como
} 
diversos artículos y monografías de Brumfield, Rosen y otros sobre la obscenidad ritual y la estrecha relación de la aischrología con los géneros literarios de la poesía yámbica y de la comedia ${ }^{21}$, cuyo tratamiento humorístico de la sexualidad y la invectiva obscena ha sido profusamente estudiado en los últimos años ${ }^{22}$, así como los valiosos trabajos de Jocelyn y Bain sobre terminología sexual concreta de la lengua griega ${ }^{23}$ o el minucioso estudio de Kapparis sobre el vocabulario de la prostitución ${ }^{24}$. Es obligado asimismo mencionar el trabajo póstumo de Bain sobre el concepto de aischrología en los autores antiguos y bizantinos y sobre su definición y tratamiento en la lexicografía moderna, especialmente el Greek-English Lexicon de Liddell-Scott-Jones (= LSJ), con sugerencias sobre cómo debería tratarse en el futuro; un trabajo

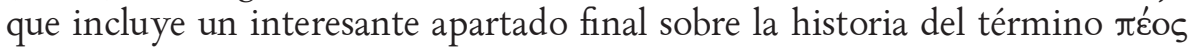

en general en la literatura y el rito, es también de provechosa lectura el trabajo de H. Herter, "Genitalien", RLAC 10, 1978, 1-52.

${ }^{21}$ Vid. A. Brumfield, "Aporreta: verbal and ritual obscenity in the cults of ancient women", en R. Hägg, ed., The Role of Religion in the Early Greek Polis: Proceedings of the Third International Seminar on Ancient Greek Cult, Organized by the Swedish Institute ar Ath-

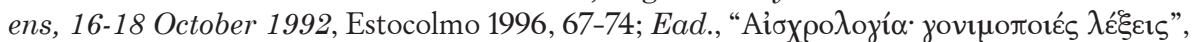

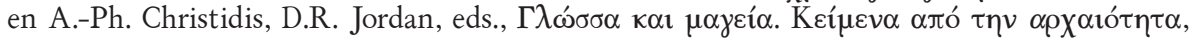
Atenas 1997, 87-93; R.M. Rosen, "Comic aischrology and the urbanization of agroikia", en R.M. Rosen, I. Sluiter, eds., City, countryside and the spatial organization of value in Classical Antiquity, Leiden 2006, 219-38; Id., "Aischrology in Old Comedy and the question of «ritual obscenity»", en M. Bastin-Hammou, Ch. Orfanos, eds., Carnaval et comédie. Actes du colloque international organisé par l'équipe PLH-CRATA, 9-10 décembre 2009, Université de Toulouse Le Mirail, Besançon 2015, 19-33; Wolfgang Rösler, "Über Aischrologie im archaischen und klassischen Griechenland“, en S. Döpp, ed., Karnevaleske Phänomene in antiken und nachantiken Kulturen und Literaturen, Trier 1993, 75-97; L. O'Higgins, Women and humor in classical Greece, Cambridge - Nueva York 2003.

${ }^{22} \mathrm{Vid}$. por ejemplo A.M. Komornicka, "Sur le langage érotique de l'ancienne comédie attique”, QUCC 9, 1981, 55-83; Enzo Degani, “Aristofane e la tradizione dell'invettiva personale in Grecia”, en J.M. Bremer, E.W. Handley, eds., Aristophanes, Vandoeuvres - Ginebra 1993, 1-49; S. Halliwell, "Aristophanic sex: the erotics of shamelessness", en M. Nussbaum, J. Sihvola, eds., The Sleep of Reason: Erotic Experience and Sexual Ethics in Ancient Greece and Rome, Chicago - Londres 2002, 120-42; Id., "Aischrology, shame and Old Comedy", en su libro Greek Laughter. A Study of Cultural Psychology from Homer to Early Christianity, Cambridge - Nueva York 2008, 215-63; J. Robson, Humour, Obscenity and Aristophanes, Tubinga 2006.

${ }^{23}$ H.D. Jocelyn, "A Greek indecency and its students: LAIKAZEIN", PCPhS 206, 1980, 12-66 (reproducido en W.R. Dynes, S. Donaldson, eds., Homosexuality in the Ancient World, Nueva York - Londres 1992, 208-62); Id., "Attic ßıveĩv and English f...", LCM 5, 1980, 65-7; Id., "Bıveiv yet again", LCM 6, 1981, 45-6; D. Bain, "Greek verbs for animal intercourse used of

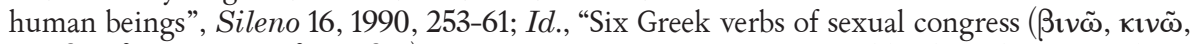

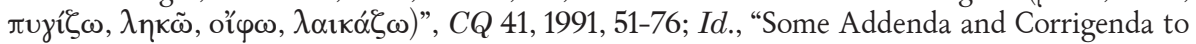
the Revised Supplement to Liddell and Scott", Glotta 75, 1999, 121-33.

${ }^{24}$ Kapparis, "The Terminology of Prostitution", que vino precedido de un riguroso comentario al discurso Contra Neera del Pseudo-Demóstenes (Apollodoros "Against Neaira" [D 59], Ed. with Introduction, Translation and Commentary, Berlín 1999 [reimpr. 2012]) y ha sido ahora ampliado y desarrollado con una completa monografía sobre la prostitución en la Grecia antigua (Prostitution in the Ancient Greek World, Berlín 2018). 
desde Aristófanes a partir de una revisión de la entrada correspondiente del LSJ, a la que añade nuevas evidencias epigráficas ${ }^{25}$. Pueden, en fin, señalarse también últimamente los útiles rapports de Kopidakis y de Janse sobre el lenguaje obsceno griego en general o el reciente libro editado por Dutsch \& Suter $^{26}$, que, aunque es una recopilación de trabajos particulares, por lo demás originales y de calidad, más que un estudio de conjunto sobre el tema, contribuye con acierto a la interpretación de numerosas referencias sexuales y escatológicas en diversos contextos (religioso, forense, teatral, satírico, etc.) del mundo griego y romano.

Pero en este cúmulo de bibliografía, que en los últimos años se muestra cada vez más extensa y pormenorizada, echamos en falta aún, como decíamos, una obra de referencia similar a la de Adams para el latín ${ }^{27}$, que trate el vocabulario erótico, sexual y obsceno del griego de manera global y exhaustiva ${ }^{28}$, sin limitarse a palabras particulares o géneros y autores concretos, ampliando y sistematizando los materiales y puntos de vista y reflexionando sobre temas generales como los distintos niveles de lengua, las diferencias léxicas entre los diversos géneros literarios, los mecanismos de formación de los diferentes campos léxicos (eufemismo, metáfora, doble sentido) y su influencia en la lengua latina (préstamos, calcos semánticos) ${ }^{29}$, los cambios diacrónicos en el interior del sistema, etc. Un trabajo lo más abarcador posible, que

${ }^{25}$ D. Bain $\uparrow$ (ed. por A. Coker), "Praefanda: the lexicography of ancient Greek aischrologia”, Eikasmos 25, 2014, 391-416.

${ }^{26}$ M.Z. Kopidakis, "Obscene language", en A.F. Christidis, ed., A History of Ancient Greek, Cambridge - Nueva York 2007, 1400-7 (y bibliografía en p. 1464); M. Janse, "Aischrology", en G.K. Giannakis, ed., Encyclopedia of Ancient Greek Language and Linguistics, Leiden - Boston 2014, vol. 1, 76-86; D.M. Dutsch, A. Suter, eds., Ancient Obscenities. Their Nature and Use in the Ancient Greek and Roman World, Ann Arbor 2015.

${ }^{27}$ Adams, Latin Sexual Vocabulary.

${ }^{28}$ En los artículos de Bain, "Low Words", 41, n. 2, y "Praefanda", 393, ambos aparecidos póstumamente, como hemos indicado, se anunciaba un extenso libro sobre el vocabulario obsceno del griego, titulado precisamente Aischrologia, que por desgracia, tras la repentina muerte del autor en noviembre de 2004, nunca se publicó.

${ }^{29}$ Es sabido que el griego se ha considerado a veces como la "lengua del amor" en la Roma de época clásica, a juzgar por algunos pasajes de Lucrecio, Marcial, Juvenal y otros autores. De hecho, entre los millares de helenismos que pueblan la lengua latina se encuentran muchos términos de la esfera erótico-sexual, tanto préstamos propiamente dichos como calcos semánticos (de palabras concretas o de imágenes y metáforas sexuales) y formas híbridas, así como muchos ejemplos "eróticos" de bilingüismo onomástico (especialmente en los epigramas de Marcial) y de code-switching (sobre todo en inscripciones pompeyanas, pero también en autores como Séneca padre o Suetonio). Sobre esta cuestión, vid. J.F. Martos Montiel, "La influencia griega en el léxico erótico latino", Ágora 16, 2014, 105-36. En este sentido, muchos de los tópicos eróticos de la literatura latina fueron tomados de -o influidos por- la lengua griega, por lo que deberá tenerse muy en cuenta la obra de R. Moreno Soldevila, ed., Diccionario de motivos amatorios en la literatura latina (siglos III a.C.-II d.C.), Huelva 2011, que, sin tratarse de un estudio léxico stricto sensu, contiene útiles listados de vocabulario y expresiones eróticas, especialmente latinas pero también griegas, y muchas entradas con abundante información y de alto interés para el trabajo que proponemos. 
recopile datos de todas las fuentes a nuestro alcance y maneje con idéntico rigor tanto los textos literarios habitualmente utilizados por los estudiosos -desde aquellos en los que son frecuentes la aischrología y las referencias sexuales, como en la comedia antigua y media, la poesía yámbica o el epigrama, hasta los géneros "serios" como la épica, la poesía coral, la tragedia, la filosofía, la historiografía, la retórica y otros algo más "ligeros" como la comedia nueva, la novela ${ }^{30}$ o la epistolografía erótica ${ }^{31}$, en los que reina el eufemismo y solo esporádicamente podemos encontrar lenguaje vulgar u obsceno- como otros materiales procedentes de fuentes distintas (inscripciones, papiros) ${ }^{32} \mathrm{y}$ de textos menos conocidos pero igualmente importantes para el conocimiento y comprensión del tema que nos ocupa: comentarios y escolios antiguos, glosas de lexicógrafos, recopilaciones de proverbios, textos populares como el

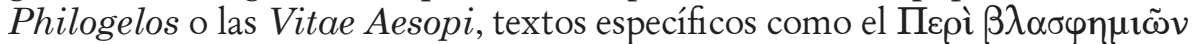

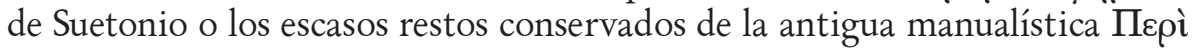
$\alpha \dot{\alpha} \rho \circ \delta \sigma^{\prime} i_{\omega} \nu^{33}$, obras técnicas de medicina, onirocrítica, fisiognómica y, por

\footnotetext{
${ }^{30}$ Paradójicamente, no contamos con ningún trabajo específico sobre el léxico erótico de la novela, un género literario tan íntimamente relacionado con el amor y la sexualidad, como ha estudiado H.L. Morales, "The history of sexuality", en T. Whitmarsh, ed., The Cambridge Companion to the Greek and Roman Novel, Cambridge 2008, 39-55. El muy discutible intento de M.G. Ciani, "Proposta metodologica per un lessico speciale”, QUCC 30, 1979, 161-71, que utilizó el libro I del Dafnis y Cloe de Longo para dar una pequeña muestra de su atrevida propuesta de elaboración de un léxico erótico de la literatura griega con un método fundado en los principios de la genética y la biología molecular (y que en puridad no distaba mucho del concepto y la práctica de la semántica contextual), pronto quedó en nada: de hecho, el prometido léxico erótico de la literatura griega (supuestamente bajo la dirección de Bruno Gentili) nunca se llevó a cabo.

${ }^{31} \mathrm{El}$ tratamiento del léxico sexual en las cartas eróticas griegas es escaso: vid. E. Suárez de la Torre, "Motivos y temas en las cartas de amor de Filóstrato y Aristéneto", Fortunatae 1, 1991, 113-32; I. Calero Secall, "Las Cartas de Alcifrón y los delitos relacionados con la conducta sexual", Prometheus 27, 2001, 153-69; D. Konstan, "Alciphron and the Invention of Pornography", en S.D. Lambert, ed., Sociable Man: Essays in Greek Social Behaviour in Honor of Nick Fisher, Swansea 2011, 323-35; Owen Hodkinson, "Epistolography", en Hubbard, Companion to Greek and Roman Sexualities, 463-78, esp. 464-70.

${ }^{32}$ Para el léxico erótico y sexual contenido en este tipo de fuentes nos parecen de interés los trabajos de Bain, "Six Greek verbs"; G. Manganaro, "Fallocrazia nella Sicilia greca e romana", $Z P E$ 111, 1996, 135-9; E. Pachoumi, "The erotic and separation spells of the magical papyri and defixiones", GRBS 53.2, 2013, 294-325; C.A. Williams, "Sexual themes in Greek and Latin graffiti", en Hubbard, Companion to Greek and Roman Sexualities, 493-508; P. Keegan, "Chapter 11: Sexuality", en su libro Graffiti in Antiquity, Nueva York 2014, 243-75; T. Sapsford, "The wages of effeminacy? Kinaidoi in Greek documents from Egypt", Eugesta 5, 2015, 103-23; S. Torallas Tovar, "Injuria y vilipendio en los papiros del Egipto Grecorromano", en

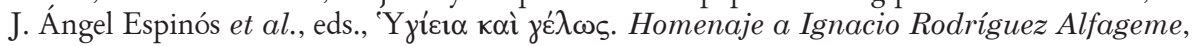
Madrid 2015, 781-94.

${ }^{33}$ Sobre el humor sexual y excremental en la Vida de Esopo, así como sobre su relación con la recopilación de chistes conocida como Philogelos, vid. C. Jouanno, "La Vie d'Ésope: une biographie comique", REG 118.2, 2005, 391-425, esp. 402-5; sobre el tratado De blasphemiis de Suetonio, junto a la introducción y a las páginas de comentario (117-149) de la edición de

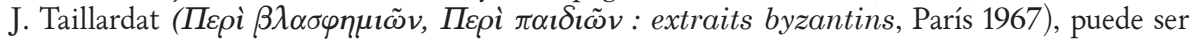


supuesto, astrología. Y es que, una vez acotado el tema y planteado como desiderátum este trabajo ideal sobre vocabulario erótico y sexual del griego, que sin duda excede las fuerzas de una sola persona y debería llevarse a cabo como una labor colectiva, el objetivo de la segunda parte de nuestro trabajo será mostrar que en él tienen cabida por derecho propio los textos astrológicos, cuya importancia en general para el conocimiento de la moral sexual de la Antigüedad y en particular para el estudio del léxico de ese campo semántico trataremos de exponer a continuación.

2. El LÉXICO ERÓTICO DE LOS TEXTOS ASTROLÓGICOS GRIEGOS: ALGUNOS EJEMPLOS.

La astrología, como es sabido, fue la más perfeccionada de las artes adivinatorias de la Antigüedad, además de una de las más populares y extendidas, desde época helenística y sobre todo en época romana e imperial ${ }^{34}$. Por esta razón, los textos astrológicos que han llegado a nosotros, desde poe-

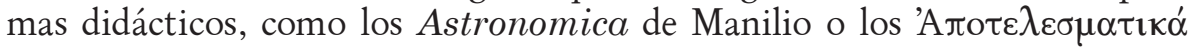
del Pseudo-Manetón, pasando por manuales técnicos para astrólogos más o menos profesionales, como las 'Av $\theta$ oגoyía de Vetio Valente o la Mathesis de Fírmico Materno, hasta sesudos tratados teóricos para consumo de científicos y filósofos, como el Tetrabiblos de Tolomeo ${ }^{35}$, alcanzan un número relativamente amplio, mucho mayor que otros tratados de tipo "científico" conservados, como manuales de onirocrítica y fisiognómica, y solo comparable con los abundantes escritos sobre medicina de esa misma época. Sin embargo, estos textos, sin duda por lo difícil -y a ratos tedioso- de su lectura, que requiere estar al tanto de los fundamentos de la astrología antigua y su complicado vocabulario técnico, han solido ser raramente leídos y escasamente manejados por la mayoría de los estudiosos, y en general poco conocidos. De hecho, a pesar de que desde finales del siglo XIX y sobre todo en la primera mitad del XX vieron la luz, tanto en primeras ediciones como en nuevas ediciones críticas, un número considerable de escritos astrológicos ${ }^{36}$, muchos

también útil el artículo de G. Carbone, "Le donne di Lesbo nel lessico svetoniano delle ingiurie (A proposito di Anacr. fr. 13 Gent.)”, QUCC 44.2, 1993, 71-6; para los escasos restos de tratados

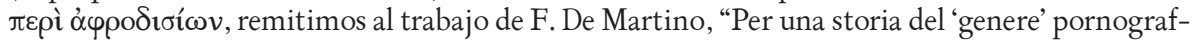
ico”, en O. Pecere \& A. Stramaglia, cur., La letteratura di consumo nel mondo greco-latino, Cassino 1996, 293-341.

${ }^{34}$ Las ideas recogidas en este párrafo y el siguiente las hemos expuesto con mayor amplitud en J.F. Martos Montiel, "Sexo y género en los textos astrológicos de la Antigüedad grecolatina”, en C. Macías Villalobos et al., eds., Europa Renascens. La cultura clásica en Andalucía y su proyección europea, Zaragoza 2015, 313-26.

35 Sin olvidar una serie de documentos, en su mayoría horóscopos, contenidos en inscripciones, papiros y ostraka, que certifican el arraigo popular de la astrología en época helenística y romana: vid. O. Neugebauer, H.B. van Hoesen, Greek Horoscopes, Philadelphia 1987.

${ }^{36}$ Destacan aquí sin duda los veinte volúmenes del Catalogus Codicum Astrologorum Graecorum (= CCAG), publicado entre 1898 y 1953 por el editor bruselense Lamertin y en el que colaboraron los más prestigiosos especialistas de la época. 
de ellos fragmentarios o en forma de resúmenes y hasta entonces de difícil acceso, solo en las últimas décadas se ha desarrollado en torno a ellos una labor de análisis, crítica y comentario lo suficientemente amplia como para que estos textos comiencen a ser estudiados de manera más extendida entre los investigadores y tenidos en cuenta con mayor frecuencia en los estudios generales sobre historia, literatura y sociedad de época helenística y roma$\mathrm{na}^{37}$. La razón fundamental de este interés estriba en que, al igual que aquellos otros escritos "científicos" a los que nos acabamos de referir, los astrológicos presentan una innegable importancia no solo desde el punto de vista lingüístico y literario, sino también como documentos históricos y sociológicos, ya que dedican buena parte de su contenido a distinguir tipos de personas y comportamientos y a clasificarlos pormenorizadamente, aplicándoles una determinada axiología moral en la que juegan un papel importantísimo los sentimientos amorosos y las pulsiones sexuales ${ }^{38}$.

En efecto, la astrología proporcionó diversas explicaciones "científicas" a las costumbres sexuales de la Antigüedad basándose en la influencia de ciertos astros que, junto con el carácter, determinarían también la actitud o gustos sexuales de las personas. En este sentido, los textos astrológicos de esta época recogen abundantes referencias al erotismo y la sexualidad e incluyen a menudo indicaciones muy precisas sobre las conjunciones y alineamientos astrales que favorecen, según sus autores, actitudes y comportamientos sexuales de todo tipo, tanto "normales" como, sobre todo, "anómalos", es decir las conductas sexuales que son objeto de reprobación, al menos por la sociedad en la que viven los astrólogos que nos hablan de ellas: nos referimos a los comportamientos lujuriosos y lascivos, tanto de hombres como de mujeres, la promiscuidad, la prostitución, las desviaciones sexuales y, por supuesto, las conductas homosexuales, con toda la variedad de tipos humanos

${ }^{37}$ Es obligado remitir aquí a la amplia bibliografía crítica recopilada por Aurelio Pérez Jiménez en el primer número de la revista $M H N H$ ("Cien años de investigación en astrología antigua”, $M H N H 1,2001,133-204)$, que con sus dieciséis volúmenes aparecidos desde entonces (y a los que remitimos también por lo que respecta a bibliografía posterior) se ha convertido sin duda en la más importante publicación científica internacional especializada en el estudio de la magia y la astrología antiguas.

${ }^{38}$ Para las convenciones morales reflejadas en los textos astrológicos, con especial atención a la moral sexual, vid. D. Konstan, "Conventional Values of the Hellenistic Greeks: The Evidence from Astrology”, en P. Bilde et al., eds., Conventional Values of the Hellenistic Greeks, Aarhus 1997. Los manuales de onirocrítica y fisiognómica a los que nos hemos referido más arriba utilizan también en muchos casos distinciones y clasificaciones similares a las de los textos astrológicos y constituyen por tanto una útil fuente de información complementaria acerca de los estereotipos de sexo y género en la Antigüedad: vid. M.W. Gleason, "The Semiotics of Gender: Physiognomy and Self-fashioning in the Second Century C. E.", en D.M. Halperin, J.J. Winkler, F.I. Zeitlin, eds., Before Sexuality: The Construction of Erotic Experience in the Ancient Greek World, Princeton, NJ 1990, 389-415, en p. 397, y "Deportment as Language: Physiognomy and the Semiotics of Gender", en su libro Making Men. Sophists and Self-Representation in Ancient Rome, Princeton, NJ 1995, 55-81, en pp. 66 s. 
que comportan (eunucos, cinaedi, hermafroditas, tríbadas, etc.). Según leemos al comienzo mismo del manual de Tolomeo (Tetr. 1.1), la astrología era absolutamente competente para pronosticar sobre las tendencias, pasiones, posibilidades y futuro de todo individuo en cualquiera de los aspectos más importantes de su vida (salud, dinero, amor, matrimonio, hijos, muerte, etc.), y por tanto el ámbito de la sexualidad no era una excepción. Antes al contrario, las indicaciones sobre costumbres sexuales son habituales en los tratados astrológicos de la Antigüedad, y especialmente, como decimos, sobre los comportamientos considerados contrarios a la norma ${ }^{39}$.

Sin embargo, al tradicionalmente escaso manejo y conocimiento de estos textos por parte de la mayoría de los estudiosos, como ya hemos señalado, se une el hecho de que, hasta la fecha, no se han analizado de manera exhaustiva y sistemática desde esta perspectiva, y solo contamos con algún capítulo esporádico en tal o cual libro ${ }^{40}$ y más recientemente con unos pocos artículos que repasan con algo más de profundidad el tratamiento de la sexualidad en determinados autores y obras astrológicas ${ }^{41}$. Ni siquiera Adams aprovechó estos textos para su pormenorizado estudio del vocabulario sexual latino, en el que solo encontramos utilizada la Mathesis de Fírmico Materno, que se limita a citar escuetamente en cuatro ocasiones para ilustrar ciertos eufemismos referentes a los órganos sexuales o alusivos al coito ${ }^{42}$. Da la impresión

${ }^{39}$ Estas explicaciones astrológicas de la sexualidad humana se mantuvieron con pocos cambios durante la Edad Media y aun después: vid. H.R. Lemay, "The Stars and Human Sexuality: Some Medieval Scientific Views", Isis 71, 1980, 127-37.

${ }^{40}$ Aparte del capítulo sobre "Les moeurs" del libro de F. Cumont, L'Égypte des astrologues, Bruselas 1937, 207-20 (citamos por la trad. italiana de G. Bezza, Milán 2003) y el escueto apartado "Sex: Polymorphous perversity" del libro de T. Barton, Ancient Astrology, Londres - Nueva York 1994, 163-6, solo conocemos el capítulo que dedica a los textos astrológicos en relación con la homosexualidad femenina el libro de B.J. Brooten, Love Between Women. Early Christian Responses to Female Homoeroticism, Chicago - Londres 1996, 115-41, junto con las breves páginas dedicadas al mismo tema en J.F. Martos Montiel, Desde Lesbos con amor. Homosexualidad femenina en la Antigüedad, Madrid 1996, 122-4, y en S. Boehringer, L'homosexualité féminine dans l'antiquité grecque et romaine, París 2007, 272-5.

${ }^{41}$ Junto al artículo de C. Macías Villalobos, "La homosexualidad y las conductas sexuales pervertidas desde la perspectiva de la astrología antigua”, Minerva 19, 2006, 215-46, centrado sobre todo en la obra de Fírmico Materno, podemos citar los más recientes de E. Calderón Dorda, "Las desviaciones sexuales en la Mathesis de Fírmico Materno", MHNH 14, 2014, 97-118, A.C. Domínguez-Alonso, "La influencia astrológica sobre la pasión amorosa en el Comentario Anónimo al Tetrabiblos de Tolomeo: edición crítica, traducción y comentario", $M H N H 15$, 2015, 253-70, D.G. Greenbaum, "From Love to Desire: The Lot of Eros in Hellenistic Astrology", $M H N H$ 15, 2015, 85-116, S. Heilen, "Sexuality and Eroticism in the Horoscopes of Antigonus of Nicaea", MHNH 14, 2014, 119-46, W. Hübner, "Gender in Ptolemy's Apotelesmatika", MHNH 14, 2014, 147-66, C. Macías Villalobos \& A. Caracuel Barrientos, "Simbolismo animal, astrología y sexualidad en los textos antiguos”, $M H N H$ 15, 2015, 141-82, y A. Pérez Jiménez, "Incesto y astrología antigua", $M H N H$ 16, 2016, 195-234, frutos todos ellos de los trabajos presentados al Congreso Internacional "Ad astra per corpora: astrología y sexualidad en el mundo antiguo", que tuvimos ocasión de organizar y celebrar en Málaga en febrero de 2015.

${ }^{42}$ Adams, Latin Sexual Vocabulary, 61 (naturale corpus [= cunnus]; necessariae 
de que Adams simplemente tomó las referencias del Thesaurus Linguae Latina $^{43}$ pero no leyó con atención la obra de Materno, en la que habría encontrado muchísimo material, al igual que en otras obras astrológicas latinas que también pasó por alto ${ }^{44}$, como hicieron con las griegas Jocelyn y Bain en sus rigurosos estudios sobre léxico sexual del griego y es práctica habitual en la bibliografía sobre el tema ${ }^{45}$.

Pero estamos seguros de que un repaso atento de los textos astrológicos, que recopile todo el vocabulario erótico y sexual que utilizan, estudie su distribución y sentidos y analice sus implicaciones literarias, históricas, sociales, culturales, etc., revelará sin duda datos novedosos y aportará interesantes enseñanzas tanto para la lexicografía griega en general como en particular para el estudio del léxico erótico y sexual de esta lengua, desde el momento en que un estudio de estas características encontrará no solo sentidos poco atestiguados hasta ahora o que no se distinguen con claridad en los principales diccionarios al uso, sino también numerosos hápax e incluso palabras no recogidas aún por la mayoría de ellos ${ }^{46}$. Y a fin de mostrar esta importancia de los textos astrológicos para el léxico sexual griego, vamos a dar a continuación, para terminar, algunos ejemplos de palabras cuyo análisis creemos que ilustrará suficientemente el estudio que aquí proponemos.

\section{$\dot{\alpha} \theta \varepsilon \mu \imath \tau о \varphi \alpha ́$ zos}

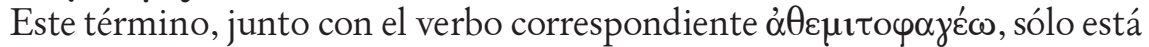
atestiguado en cinco ocasiones, todas ellas en obras astrológicas, con el sentido esperable, dada la etimología del compuesto ( $\alpha \theta \dot{\varepsilon} \mu \imath \tau o \varsigma$, forma tardía de

partes, [loca] necessaria), 160 (matrimonium $[=$ concubitus $]$ ) y 176 (intrare ad $[=$ coire, futuere]).

${ }^{43}$ Cf. Adams, Latin Sexual Vocabulary, 160, n. 5: "See $T L L$... for similar examples in Maternus".

${ }^{44}$ Por dar un simple ejemplo, tanto en la Mathesis de Fírmico Materno (3.5.23; 11.11; 4.6. $4 ; 6.30 .15 ; 7.25 .4 ; 5 ; 11 ; 13 ; 8.9 .1 ; 27.9)$ como en el Liber Hermetis de triginta sex decanis, conocido también como Hermes Latinus (25.6.16; 32.71), encontramos tres términos distintos (virago, fricatrix, crissatrix) para referirse a la tríbada o lesbiana, ninguno de los cuales es mencionado por Adams.

${ }^{45}$ Tan solo Jocelyn, "A Greek indecency", 26, n. 155, mencionaba de pasada algunos pasajes de Vetio Valente, Retorio, Tolomeo y el Pseudo-Manetón referidos a sexo oral, sin detenerse a comentar sobre ellos más que el hecho general (y obvio por esperable) de que estos autores, al igual que otros (Dión de Prusa, Artemidoro), prefirieron hablar de este tema con "polite periphrasis". Krenkel sí utiliza de vez en cuando fuentes astrológicas, pero sus esporádicas referencias, por ejemplo en Krenkel, “Tonguing”, 38-9 y 44, carecen de profundidad y, en la línea de Jocelyn, no pasan de señalar los "general and unspecified terms" en que, según él, suelen expresarse estos textos.

${ }^{46}$ En J.F. Martos Montiel, “Un hápax 'astrológico' griego no recogido en los diccionarios:

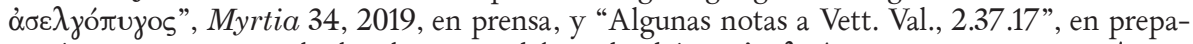

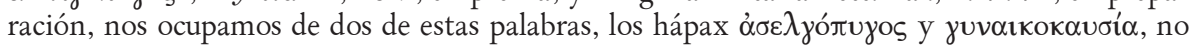
incluidos por tal razón en el presente trabajo. 


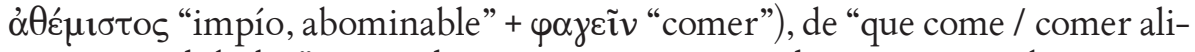
mentos prohibidos", normalmente con un matiz religioso, como observamos

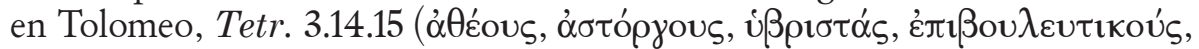

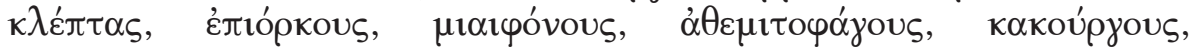

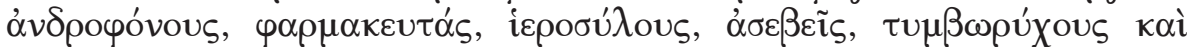

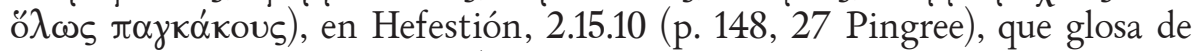

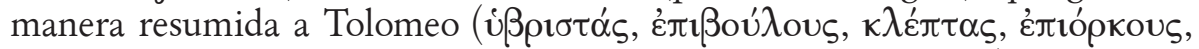

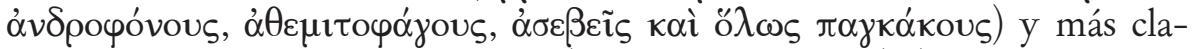

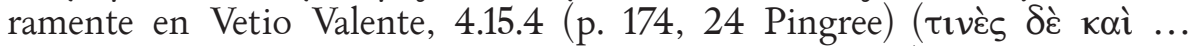

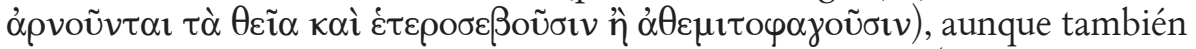

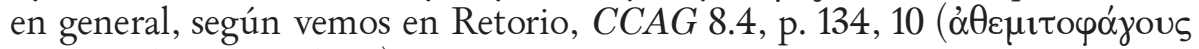

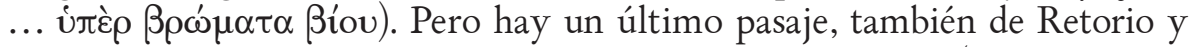
al que nos referiremos en más de una ocasión más adelante $(C C A G 8.4$, p.

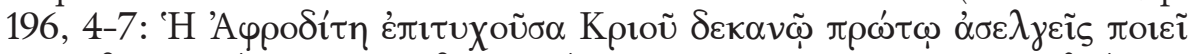

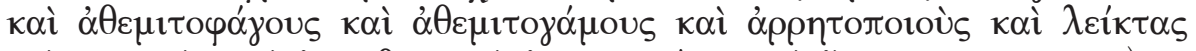

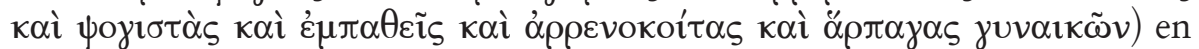
el que nuestro vocablo parece utilizarse más bien como un eufemismo para referirse a alguna actividad sexual considerada abominable o depravada, probablemente felación o cunnilingus, a juzgar por la aparición, en la misma frase (cuyo tenor sexual es evidente) y casi inmediatamente, de los térmi-

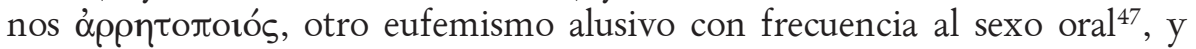

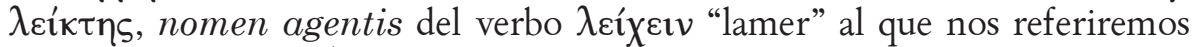

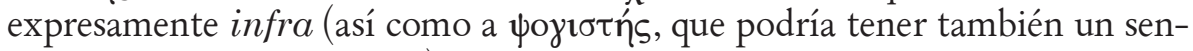
tido sexual, como veremos). Por lo que sabemos, ningún diccionario recoge hasta ahora este matiz que apuntamos.

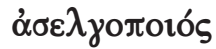

También son textos astrológicos los únicos que en cuatro ocasiones atestiguan este adjetivo, de sentido claro ("que produce [o induce a] depravación o impudicia") y referido, en el título de capítulos sobre la influencia astral en

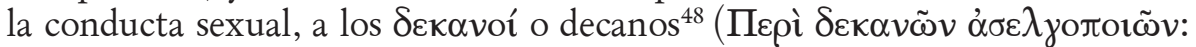
Antíoco, $C C A G 7$, p. 115, 9; 8.3, p. 109, 13; Retorio, CCAG 8.4, p.196,3). Pero

${ }^{47}$ No solo a felación, como indican sub voce Vorberg, Glossarium eroticum, y el suplemento del LSJ (el Diccionario Griego-Español de Adrados [= DGE] da simplemente "que practica un vicio obsceno o vergonzoso", sin mayor especificación), sino también a cunnilingus,

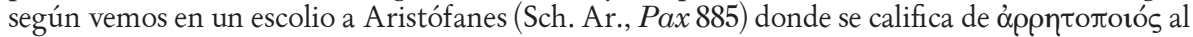
ateniense Arífrades, a quien atacaba el comediógrafo (también, y más claramente, en Eq. 1280 ss.) por su gusto por tal práctica sexual; sobre el personaje y la práctica, a los que nos referiremos más adelante, vid. E. Degani, "Arifrade l'Anassagoreo", Maia 12, 1960, 190-217; Michele Na-

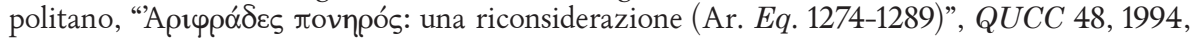
67-92; T. Gargiulo, “Aristofane, Eq. 1289”, QUCC 58, 1998, 11-13.

${ }^{48}$ En el vocabulario técnico de la astrología, se llama así a cada uno de los tres sectores de $10^{\circ}$ que resultan de la división de los $30^{\circ}$ de cada signo del círculo zodiacal y que se adjudican a determinados planetas o a las luminarias: vid. Neugebauer, van Hoesen, Greek Horoscopes, $5 \mathrm{~s}$. 
esta referencia específica a los decanos no es la única documentada, como parece dar a entender la redacción de la entrada $\alpha \sigma \varepsilon \lambda$ yo tantes diccionarios ${ }^{49}$, pues en el cuarto pasaje documentado (Retorio, $C C A G$

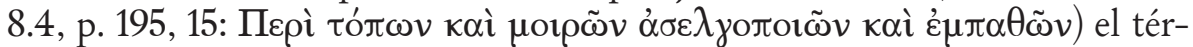
mino, con el mismo sentido e igualmente como parte de un título, se refiere de manera genérica a los "lugares y partes" en que se divide el zodiaco, y en este caso coordinado con el adjetivo غ̇ $\mu \pi \alpha \theta \eta \dot{s}$, de sentido también algo más

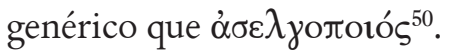

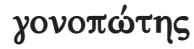

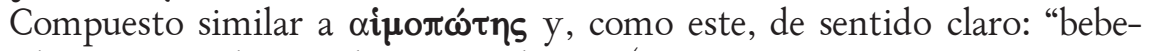
dor de semen", tal como lo recoge el DGE (cf. s. v. yóvos B I 1: "semen, esperma"), mientras que el LSJ lo traduce pudorosamente al latín ("qui semen bibit”). Se trata de un hápax conservado en el poema astrológico del PseudoManetón, en un pasaje (4.309-16) en el que se enumeran una serie de vicios y conductas depravadas a las que tienden los nacidos bajo el influjo combinado de Venus, Marte y Saturno. Entre estos vicios, el primero que se menciona de forma explícita, tras un genérico $\pi \alpha \mu \pi \alpha \theta \varepsilon \varepsilon_{\varsigma}$, es el del gusto por el sexo oral:

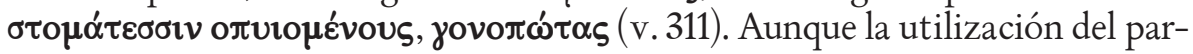
ticipio medio-pasivo de ótuíc en la perífrasis inicial podría hacer pensar que el poeta distingue entre actos de irrumación y actos de felación, nos parece más acertado ver aquí una distinción entre cunnilingus y felación, como considera Jocelyn, y más si tenemos en cuenta que la expresión similar ß̧veĩv

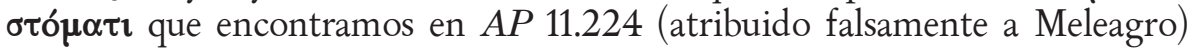
se refiere sin duda a cunnilingus, como ha demostrado Bain ${ }^{51}$. En todo caso, ha de señalarse que la referencia al sexo oral no acaba en ese verso, sino que

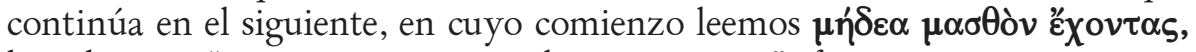
literalmente "que tienen por teta las vergüenzas", frase que no parece que corresponda a una tercera distinción dentro de la clase de personas inclinadas al vicio oral ${ }^{52}$, sino más bien a una despectiva y un tanto grosera calificación

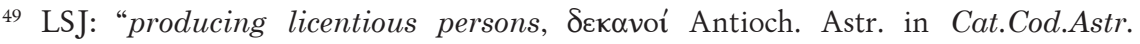

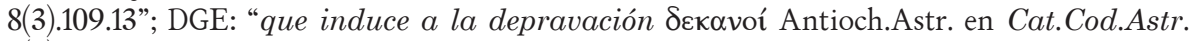
8(3).109.13".

${ }^{50}$ Frente al LSJ y el DGE, el Lexikon zur byzantinischen Gräzität (= LBG) de Trapp sí indica esta circunstancia a la que nos referimos, aunque no de manera completa: "Zügello-

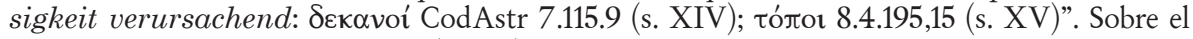

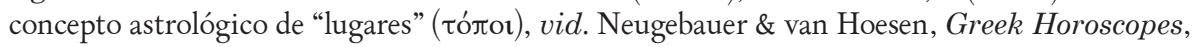
$7 \mathrm{~s}$.

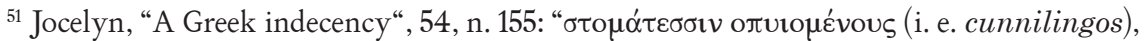

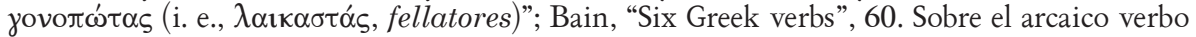
ỏ tuíco, "casar(se)", que a veces se utiliza en sentido sexual con cierto tono vulgar aunque no tan fuerte como ßıvéw, vid. Henderson, Maculate Muse, 157, P. Edwards, "Meaning and aspect in the verb óđuíw”, Minos, 20-22, 1987, 173-81, y Bain, "Six Greek verbs”, 57.

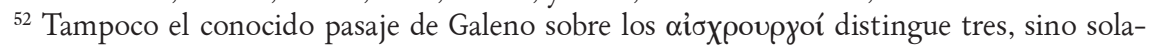


genérica. De las dos únicas traducciones modernas que conocemos del poema de Manetón, la latina de Gronovius, que acompañaba a su editio princeps (Leiden 1698), y la italiana de Anton Maria Salvini, de principios del XVIII ${ }^{53}$, la primera ofrece solamente "Omnia patientes, fellatores..." y deja con puntos suspensivos el resto del verso 311 y el comienzo del siguiente, mientras que la segunda traduce el fragmento por "Pazienti tutto, nella bocca usati, / cui poppa son le naturali cose” (p. 86, vv. 438 s.), dejando también sin traducir el término yovo $\pi \omega ́ \tau \alpha \varsigma$, lo que apoya pensar que esta sería la palabra más malsonante dentro de un pasaje fuertemente obsceno.

\section{$\delta 1 \alpha \tau i \theta \eta \mu r$}

Un evidente sentido sexual de este verbo puede apreciarse en diversos pasajes del Tetrabiblos de Claudio Tolomeo en los que se utiliza a la vez formas activas y pasivas de $\delta \imath \tau \tau i ́ \theta \eta \mu$ para distinguir la relación sexual activa de la pasiva: así en Tetr. 3.14.17, al referirse Tolomeo a individuos "inmorales en las relaciones activas y pasivas tanto naturales como contra natura, deseosos de

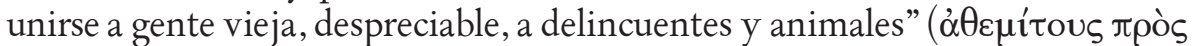

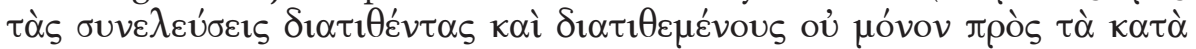

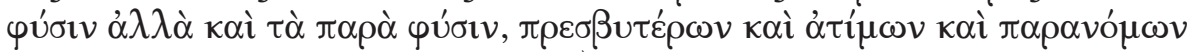

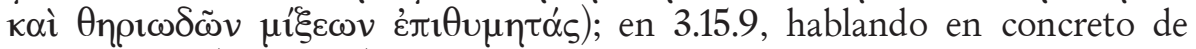
las lesbianas ( $\tau \rho \mathbf{\beta} \alpha \dot{\delta} \delta \varepsilon \varsigma$ ), que "tienen trato con mujeres y realizan actos de hombres ... abiertamente, de manera que a veces incluso designan como

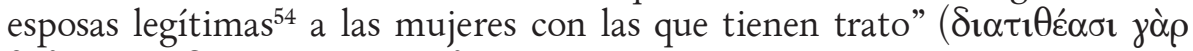

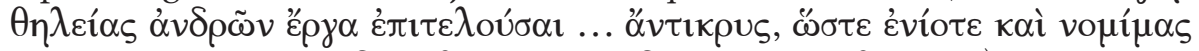

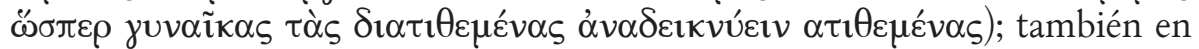
4.5.13, de nuevo refiriéndose en general a individuos "pervertidos y dispues-

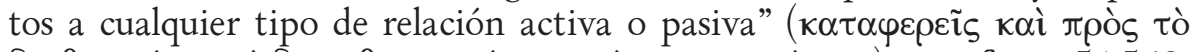

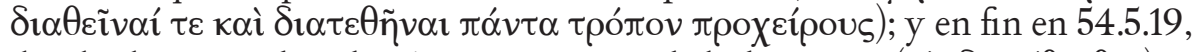

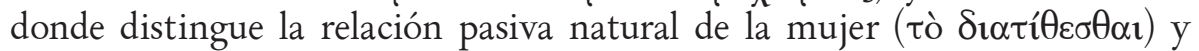

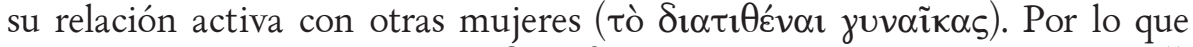
sabemos, este sentido sexual de $\delta \iota \alpha \tau i ̂ \eta \eta \mu$ apenas aparece en otros autores ${ }^{55}$,

mente dos tipos de personas aficionadas al sexo oral, los feladores y los que practican el cunnilin-

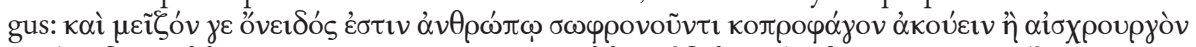

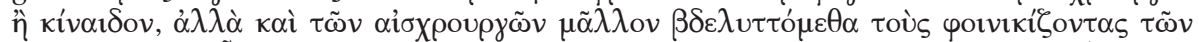

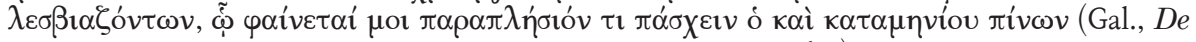
simpl. medic. temperamentis ac facultatibus 12.249.9-13 Kühn).

${ }_{53}$ Manetone, Degli effetti delle stelle, [traduzione di] Anton Maria Salvini, a cura di Rosario Pintaudi, Florencia 1976.

${ }^{54}$ Sobre la cuestión de la posible existencia de matrimonios homosexuales entre mujeres, $c f$. el famoso diálogo lucianesco entre Megila y Leena (Luc., DMer. 5), donde Megila dice expre-

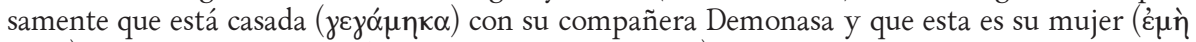
子uvń), y vid. Martos Montiel, Desde Lesbos con amor), 116-20.

${ }_{55}$ Solo lo hemos detectado en el Erótico de Plutarco, en un pasaje (Mor. 768 E [= Amat. 23]) en el que se distingue entre varones homosexuales pasivos ( 
pero está íntimamente ligado al sentido técnico que encontramos en gramáticos como Apolonio Díscolo, quien utiliza a menudo el verbo en sus diátesis activa y pasiva para indicar, respectivamente, el "sujeto" o el "ser activo o

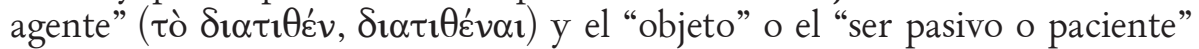
( recogido en algunos de los grandes diccionarios de referencia ${ }^{56}$, pero ninguno de ellos refleja el sentido sexual que hemos señalado, lo que supone en nuestra opinión una grave carencia que debería corregirse lo antes posible.

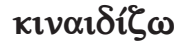

Aparte de en un antiguo escolio a Aristófanes, Paz 1295 ss., para explicar una pulla lanzada por el comediógrafo contra el político ateniense Cleóni-

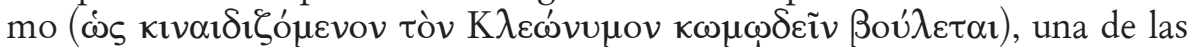

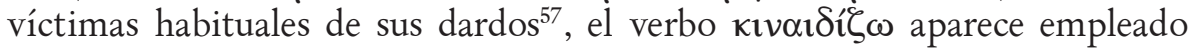
solamente dos veces en toda la literatura griega de la Antigüedad y la Edad Media que ha llegado hasta nosotros, y en ambas se trata de textos astrológicos. Hablamos concretamente de un pasaje de Antíoco de Atenas en uno de los fragmentos de sus Tesoros transmitidos por el códice Monac. 287

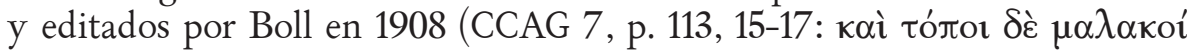

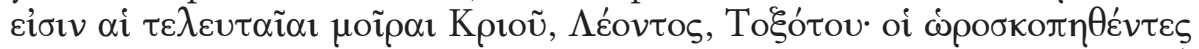

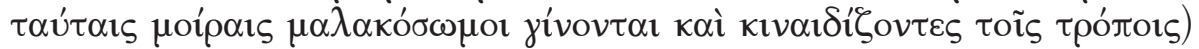
y otro de Retorio, transmitido fundamentalmente en el códice Parisinus 2425 (P) editado por Cumont en 1921 (CCAG 8.4, p. 195, 21-196, 2: кaì

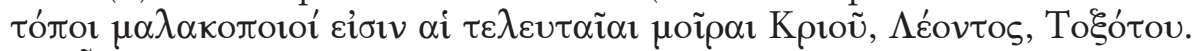

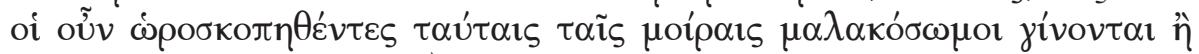

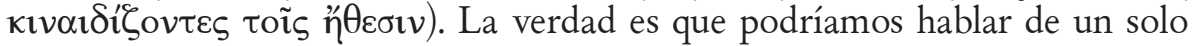
pasaje, pues el de Retorio no es más que una glosa del de Antíoco, como ocurre a menudo con estos autores ${ }^{58}$, y además en este segundo la palabra que nos

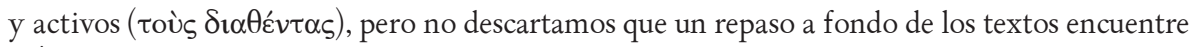
más testimonios.

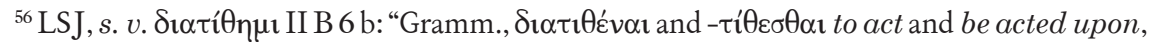

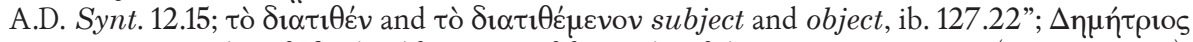

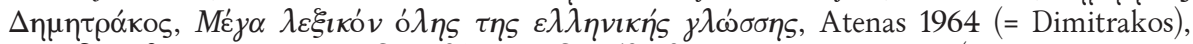

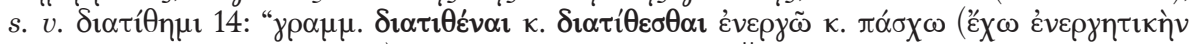

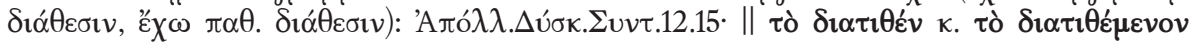

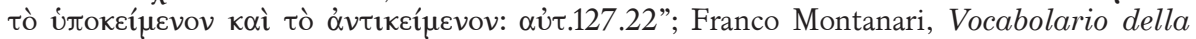

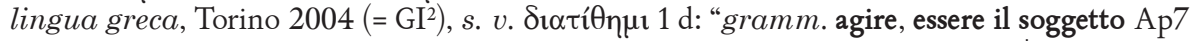

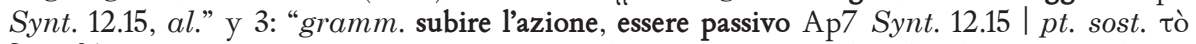

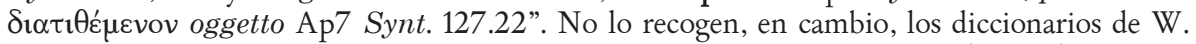
Pape, Handwörterbuch der griechischen Sprache, Braunschweig $1914^{3}$ (= Pape), Anatole Bailly, Dictionnaire grec-français, París $1950^{16}$ (= Bailly) ni, sorpresivamente, el DGE.

${ }^{57}$ Pero también para otros autores: cf. Eup., fr. 352 K.-A.; adespota fr. 1151 K.-A.

${ }^{58} \mathrm{Vid}$. lo que escribe Cumont al respecto en $C C A G$ 8.4, pp. 115 ss.; sobre el intrincado problema de deslindar la obra de uno y otro autor, $c f$. David Pingree, "Antiochus and Rhetorius", CPh 72, 1977, 203-23. 


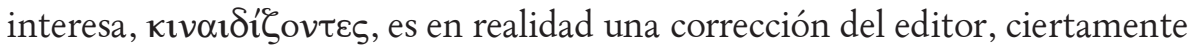
acertada ante la lectura evidentemente errónea, tanto en la acentuación como

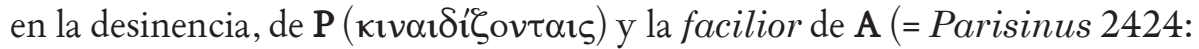

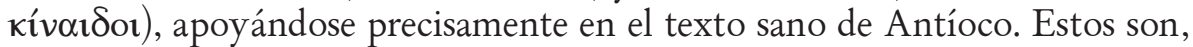
por tanto, los únicos testimonios del verbo kıvaı $\delta i \zeta \omega$, que formalmente es un evidente denominativo del término kívoıঠos, pero que en el plano semántico, y por esa misma razón, podría plantear en principio ciertos problemas de intelección y traducción, pues es sabido que kívaidos suele entenderse modernamente como "homosexual pasivo", y consecuentemente entienden así también el verbo los diccionarios que lo recogen, como LSJ ("practice unnatural vice") o GI ("prostituirsi"), pero en realidad el sustantivo se aplicaba en general a personas de carácter promiscuo o de costumbres sexuales depravadas y se asociaba también a menudo con el simple afeminamiento ${ }^{59}$. $\mathrm{Y}$ creemos que es más bien a este último sentido al que apunta nuestro verbo en los pasajes que lo atestiguan, tanto en los astrológicos, por su estrecha relación en ellos con la palabra $\mu \alpha \lambda \alpha$ kós "blando, afeminado" y derivados ( $\mu \alpha \lambda \alpha \kappa o ́ \sigma \omega \mu o 1, \mu \alpha \lambda \alpha \kappa o \pi$ oเoí), como en el escolio a la Paz, pues ni en esta ni en ninguna otra comedia de Aristófanes ni de otros comediógrafos contemporáneos se critica a Cleónimo por ser sexualmente depravado, sino por su glotonería y cobardía ${ }^{60}$, lo que en todo caso implicaría blandura y afeminamiento, pero no expresamente prostitución homosexual.

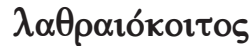

De nuevo estamos ante un hápax que sólo aparece en un texto astrológico, esta vez el de Vetio Valente, en un pasaje $(2.17,62$, en p. 72, líneas 19-24 Pingree) donde se nos describe cómo la influencia combinada de Venus y Saturno produce individuos sexualmente promiscuos, tanto hombres inces-

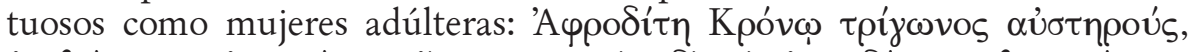

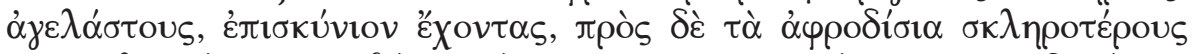

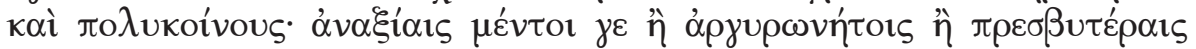

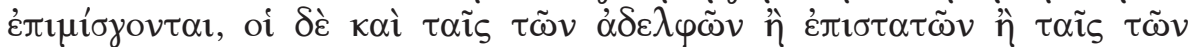

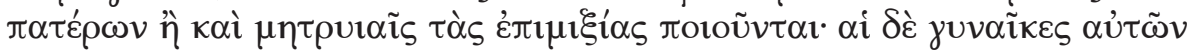

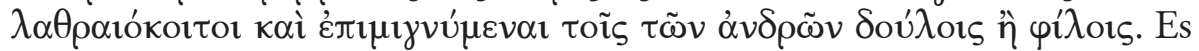

${ }^{59}$ Para el sentido del término kívaıঠos sigue siendo fundamental el artículo de W. Kroll, "Kinaidos", $R E, 11.1,1922,459-62$; remitimos también a Martos Montiel, "La influencia griega”, 112-13, donde señalamos ulterior bibliografía, a la que conviene añadir el comentario de É. Bernand, Les inscriptions de Philae II, París 1959, $\mathrm{n}^{\circ} 154$, las consideraciones de F. Perpillou-Thomas, "Artistes et athlètes dans les papyrus grecs d'Égypte", $Z P E$ 108, 1995, 225-51, en esp. 228-9, y la más reciente discusión de Sapsford, "The wages of effeminacy".

${ }^{60}$ Sobre estas críticas a Cleónimo en la comedia ática vid. M. Ornaghi, "Un bersaglio esclu-

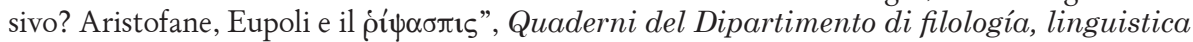
e tradizione classica "Augusto Rostagni» n. s. 7, 2008, 39-52, y G. Cuniberti, "Le accuse di corruzione e concussione nella satira politica di Aristofane”, Aevum 88, 2014, 3-18. 
evidente que nuestro término es un compuesto del adjetivo $\lambda \alpha \theta \rho \alpha$ ĩos, "secreto, furtivo", y el sustantivo koí ๆ "lecho" o "acción de yacer", de donde "unión sexual", y tiene por tanto un sentido estrechamente relacionado con

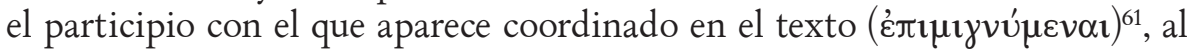
que añade simplemente el matiz del secreto, habitual por lo demás en una relación de adulterio, por lo que nos parece acertada la traducción que da Riley de la frase que lo contiene, al final del pasaje citado: "Their wives sneak off and lie with their husbands' slaves or friends" 62 . El LSJ recoge el término, traduciéndolo por "adulterer, fornicator" y citando el pasaje de Valente (por la numeración de la edición de Kroll), pero se equivoca al lematizar la palabra (al igual que la base de datos del Thesaurus Linguae Graecae [= TLG]), pues no se trata de un sustantivo masculino, como indica $(\lambda \alpha \theta \rho \alpha$ เókor $\tau$ os,

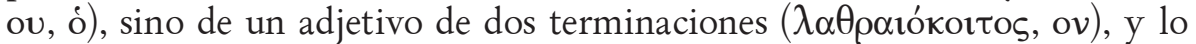
mismo encontramos en $\mathrm{GI}^{2}$, que parece haber copiado la entrada tal cual la encontró en LSJ (pues traduce "adultero, fornicatore" y mantiene en la cita la numeración de Kroll), y en Dimitrakos, que ofrece solamente el masculino " $\mu$ orxós" (cuando existe en griego moderno la forma femenina $\mu$ orx $\alpha \lambda$ ís,

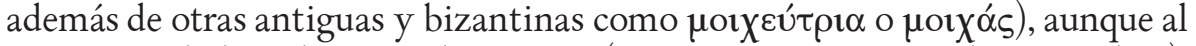
menos añade la indicación de " $\mu \tau \gamma \nu . "(=\mu \varepsilon \tau \alpha \gamma \varepsilon v \varepsilon ́ \sigma \tau \varepsilon \rho o v$, es decir "tardío"). Es urgente, por tanto, enmendar esta entrada en los diccionarios al uso corrigiendo su lematización e indicando (con un simple fem. tras ella bastaría) que la palabra aparece usada en femenino en el único lugar en el que se atestigua.

\section{$\lambda \varepsilon i ́ \kappa \tau \eta \varsigma$}

Como indicábamos más arriba, se trata del nomen agentis de $\lambda \varepsilon i ́ x \varepsilon ı v$ "lamer", un verbo que, aunque nunca llegó a perder su sentido propio, se usó a menudo para referirse al sexo oral, particularmente a su "variante fenicia”, como dice Jocelyn, es decir al cunnilingus ${ }^{63}$, por lo que se trataría,

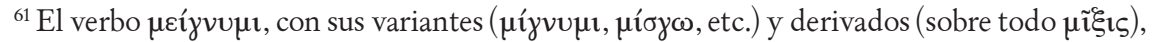
es un conocido eufemismo para la relación sexual de cierto tono culto y extendido uso literario (documentado ya desde Homero) y médico (desde el mismo Hipócrates), que influyó sin duda en el uso del latín misceo y compuestos: vid. Henderson, Maculate Muse, 156; Adams, Latin Sexual Vocabulary, 180 s.; Martos Montiel, "La influencia griega", 119. Para su uso específico en escritos médicos, vid. Catonné, "Étude du vocabulaire sexuel hippocratique", 342-5; sobre su uso especialmente extendido en la historiografía, vid. V. Ramón Palerm, "Éros femenino en

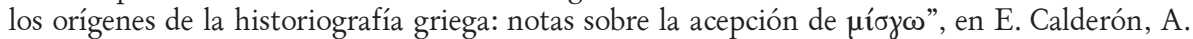
Morales, M. Valverde, eds., Koinòs lógos. Homenaje al profesor José García López, Murcia 2006, 867-72.

${ }^{62}$ Vettius Valens, The Anthology, trad. inglesa online de M.T. Riley, diciembre 2010 <http://www.csus.edu/indiv/r/rileymt/Vettius>, 33.

${ }^{63}$ Cf. Jocelyn, "A Greek indecency“, 20 s. (su "Phoenician type" es una alusión al verbo

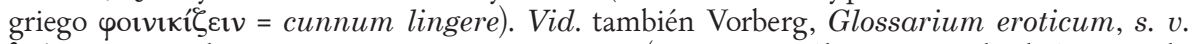

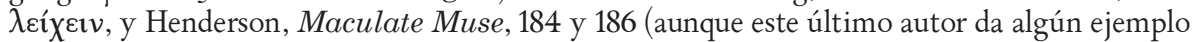
de $\lambda_{\varepsilon i ́} \chi \varepsilon ı v$ fellare que nos parece muy discutible; mucho más claro puede ser, entre otros, el que se encuentra en SEG 38:749,16: un grafito del siglo IV a.C. procedente del norte del Mar
} 
si no de una obscenidad fundamental, sí de un término fuertemente mal-

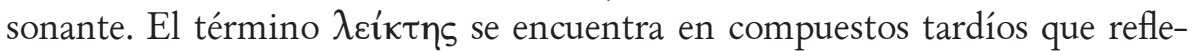
jan esa fluctuación de la raíz $\lambda \varepsilon^{i} \chi^{-}$entre su sentido propio y el obsceno,

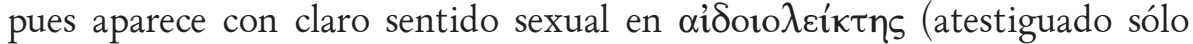
una vez en el Léxico de Hesiquio) ${ }^{64}$ pero también en los nombres propios

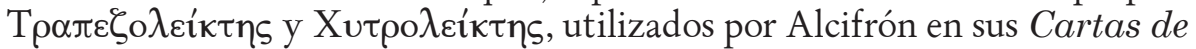
parásitos (3.9 y 18) como nombres parlantes para aludir a la glotonería de dos gorrones ("Lamemesas", "Lameollas"). Como término simple, en cambio, $\lambda \varepsilon i$ i $\tau$ s parece haberse especializado en el uso obsceno, puesto que, de las cuatro ocasiones en las que se atestigua, tres son, como veremos enseguida, textos astrológicos referidos a prácticas sexuales consideradas abominables y

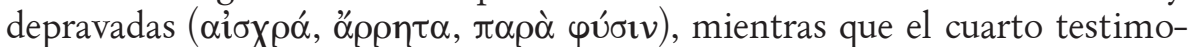
nio no deja lugar a dudas sobre el sentido del término, pues se trata de un escolio a Aristófanes, Paz 885, en relación con Arífrades, el famoso cunni-

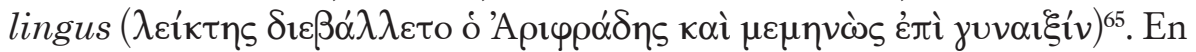
cuanto a los textos astrológicos, a uno de ellos ya nos hemos referido antes

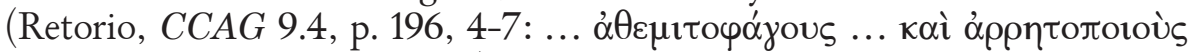

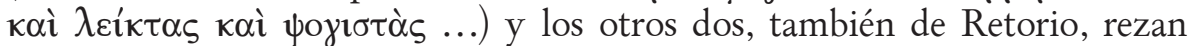

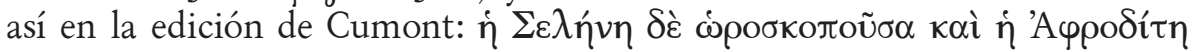

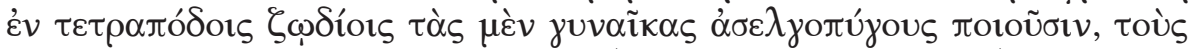

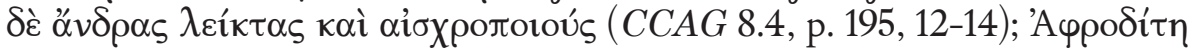

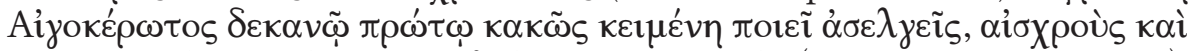

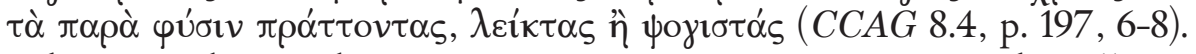
Del primero de estos dos textos nos ocupamos por extenso en otro lugar ${ }^{66}$, por

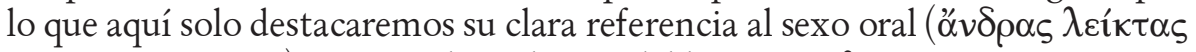

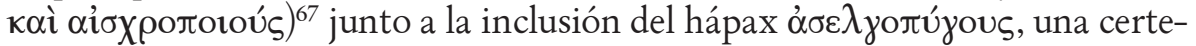

Negro en el que se lee Eü $\left.\mu \eta[\lambda o \varsigma] \ldots / \tau \grave{\alpha} \nu \psi[\omega \lambda \grave{\alpha} v] / \lambda \varepsilon^{i ́ x}[\varepsilon 1]\right)$. Diversos compuestos del verbo

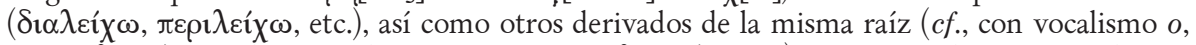

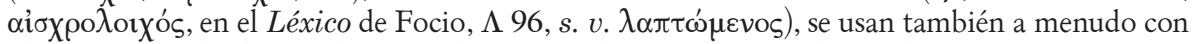
el mismo sentido alusivo al sexo oral, en general, y en concreto al cunnilingus.

${ }^{64}$ Hsch., $\Sigma$ 928, s. $v$. бкعрós. No está claro si este término se refería en general a sexo oral o específicamente a felación, a juzgar por la entrada que le sigue en la obra de Hesiquio

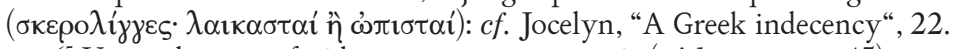

${ }^{65} \mathrm{Ya}$ nos hemos referido antes a este personaje (vid. supra, n. 45); por si quedaba duda, la afición que se le critica queda meridianamente clara en otro escolio (Sch. Ar., Eq. 1289): Si⿳亠口

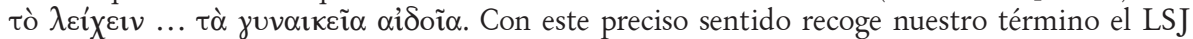

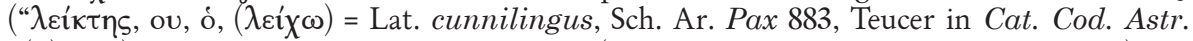

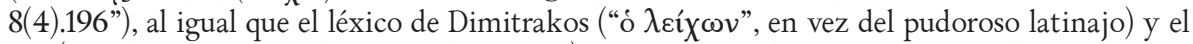
$\mathrm{GI}^{2}$ (que da, más apropiadamente, "leccatore"), pero no, por ahora, ningún otro diccionario. La mención en LSJ de "Teucer" (es decir, Teucro de Babilonia, astrólogo egipcio de época helenística, cuyos escritos pueden fecharse en torno al 100 a. C.) es poco clara, pues en realidad se trata de un texto de Retorio, cuya fuente parece haber sido Teucro: vid. la nota de Cumont en CCAG 8.4, p. 196, así como Pingree, "Antiochus and Rhetorius", 220.

${ }^{66}$ Martos Montiel, "Un hápax ‘astrológico”.

${ }^{67}$ Es decir, hombres que practican el cunnilingus y quizá también la felación. Al igual que 


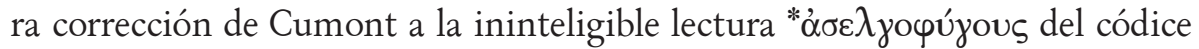
Paris. gr. 2425, que contiene el texto de Retorio, para aludir a mujeres que se entregan al coito a tergo, posiblemente con penetración anal ${ }^{68}$. En cuanto

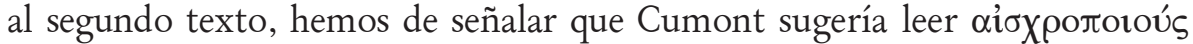
en vez de $\alpha i \sigma x \rho o u ́ \varsigma^{69}$, lo que, aunque no nos parece estrictamente necesario, en todo caso acentuaría la referencia a sexo oral de toda la frase, y corregía

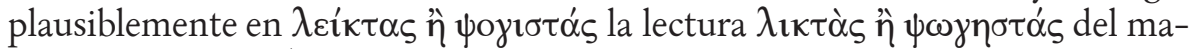
nuscrito parisino (no de otros, que recogen la frase omitiendo estas últimas palabras $)^{70}$, pero se equivocaba en la explicación de nuestro término (y proba-

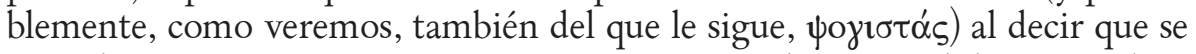
trata de "fellatores et cinaedi", puesto que, según hemos podido comprobar,

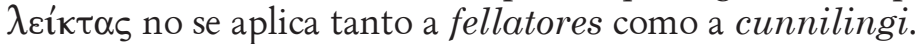

\section{$\mu \alpha \lambda \alpha \kappa o ́ \sigma \omega \mu$ s}

Los dos formantes de este adjetivo tardío son muy frecuentes en composición, tanto $\sigma \tilde{\omega} \mu \alpha$ "cuerpo", como $\mu \alpha \lambda \alpha \kappa o ́ s ~ " b l a n d o$, flojo, débil, delicado", de donde, en sentido figurado y aplicado in malam partem a personas, "afe-

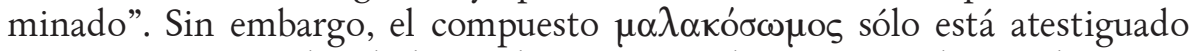
en tres ocasiones, dos de las cuales corresponden a textos de astrología, en

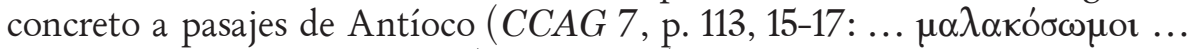

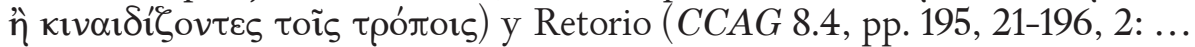

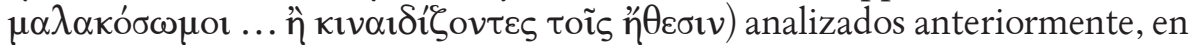
los que la presencia del verbo $\kappa \iota v \alpha i \delta i \zeta \omega$ deja claro el sentido sexual negativo con el que se utiliza nuestro término; y tal sentido, además, solo aparece en estos textos, pues en el tercer testimonio de $\mu \alpha \lambda \alpha \kappa o ́ \sigma \omega \mu o \varsigma$, que se encuentra en el tardío Epítome médico de Pablo de Egina (un tratadista de medicina del siglo VII que escribió una extensa enciclopedia del saber médico en la que resumía los trabajos de Galeno y Oribasio), dentro de una breve descripción de las propiedades cicatrizantes del yeso, se aplica a "personas endebles" (غ̇ंì $\tau \tilde{\omega} \nu \mu \alpha \lambda \alpha \kappa o \sigma \omega \mu \omega \nu)$, sin mayor especificación, pero con un evidente sentido fisiológico totalmente neutro ${ }^{71}$.

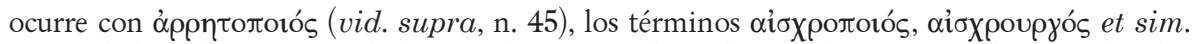
se usan habitualmente para aludir no solo en general a todo tipo de actos sexuales considerados antinaturales o depravados, sino concretamente a prácticas de sexo oral, normalmente felación, pero también a veces cunnilingus: vid. Vorberg, Glossarium eroticum, s. vv.; Krenkel, "Fellatio and irrumatio", 77 s., y "Tonguing”, 37; Jocelyn, “A Greek indecency”, 18 y passim.

${ }^{68}$ A juzgar no solo por el sentido propio del término, sino también por la presencia en

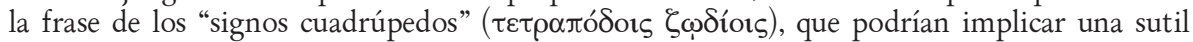
alusión a dicha postura sexual: vid. Martos Montiel, "Un hápax 'astrológico"”.

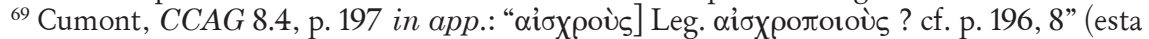
última referencia debería ser en realidad "p. 196, 9").

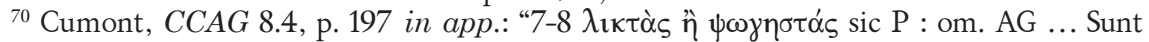

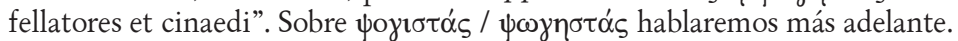

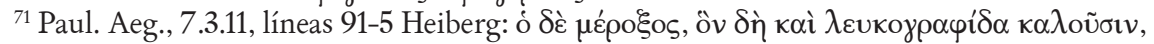




\section{$\pi \alpha \theta$ ıкós}

Tenía razón Adams al sugerir que el latín pathicus debió ser un préstamo popular (más o menos sinónimo, por cierto, de cinaedus, otro préstamo griego), pero se equivocaba al señalar que $\pi \alpha ́ \sigma \chi \omega$, el verbo sobre cuya raíz se forma $\pi \alpha \theta$ ıós, "es raro en un sentido sexual", y sobre todo al afirmar que este término "no está documentado en griego"72. El error de Adams tiene una justificada disculpa, pues en el momento en que él escribía sólo se conocía una esporádica aparición del término en un glosario latino-griego atribuido falsamente al gramático Filóxeno (siglo I a. C.) y conservado en un manuscrito parisino del siglo IX editado por Goetz y Gundermann (Corpus Glossariorum Latinorum, vol. II, Leipzig 1888, p. 130, 58: morbosus $\pi \alpha \theta \imath$ «ós) y otra en una oscura obra de mediados de época medieval, el poema astrológico del sabio Juan Camatero, patriarca de Constantinopla entre 1198 y 1206, en un pasaje (Introductio ad astronomiam 2897-901) que dice así:

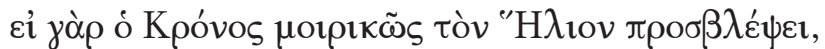

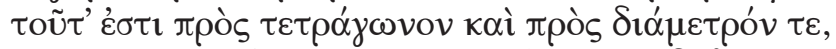

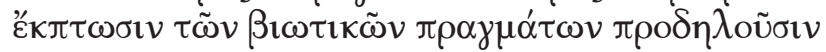

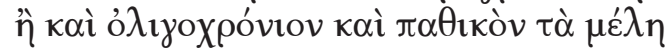

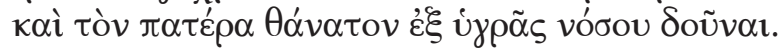

Aunque cabe suponer que los lexicógrafos modernos pasaran por alto tales obras por puro desconocimiento, parece más verosímil pensar que fue lo tardío de estos testimonios lo que llevó a la práctica totalidad de los grandes diccionarios a redactar la entrada $\pi \alpha \theta$ ıós limitándose al uso en latín del

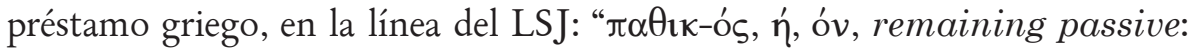
hence Lat. pathicus, i.e. qui muliebria patitur, Iuv. 2.99, etc.”, corregido luego en el revised supplement de 1996: "in sexual sense, pathic, in Lat.

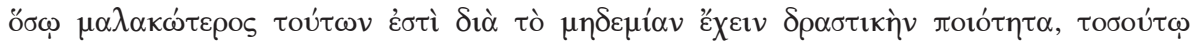

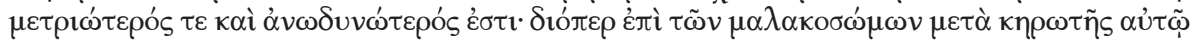

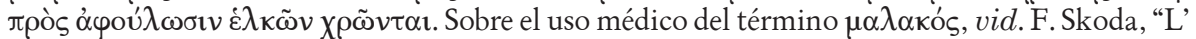
expression de qualités physiques et de propriétés efficientes: les emplois médicaux de $\mu \alpha \lambda \alpha$ kós,

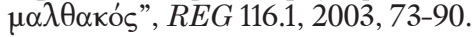

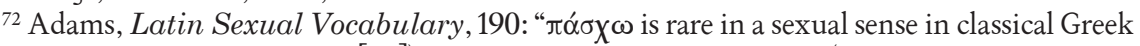
(but note Aristoph. Thesm. 201[...]). $\pi \alpha \theta$ เ kós is not quoted in Greek (but note Nicarchus, AP

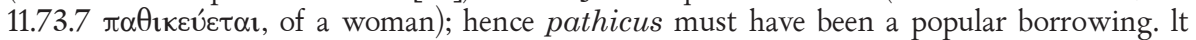
was in vulgar use (CIL 4.2360, 11.6721.39). Pathicus was applicable to males (Catull. 16.2, Iuv.

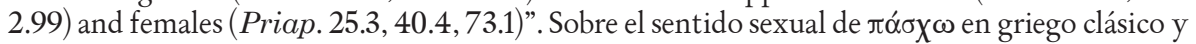
posterior para referirse particularmente al eros homosexual, vid. Henderson, Maculate Muse, 158 y 210, y especialmente Manuel González Rincón, Estratón de Sardes. Epigramas, Sevilla

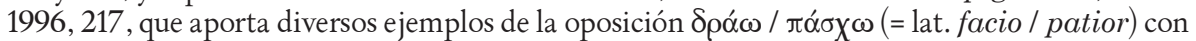
sentido erótico, i. e. "dar" / "tomar, recibir". 
form pathicus, Cat. 16.2, 57.2, Iuv. 2.99"73. El único diccionario actual que recoge las referencias a los textos tardíos que hemos señalado supra, es decir el glosario del Pseudo-Filóxeno y el poema de Camatero, es el léxico bizantino de Trapp (LBG): " $\pi \alpha \theta$ ıós unzüchtig: CorpGloss 2.130,58. KamAst 2900”. Pero aquí surge un problema, y es que la traducción alemana que ofrece esta entrada (unzüchtig "impúdico, obsceno") tiene todas las trazas de haberse visto influida erróneamente por el significado sexual del pathicus latino, único presente, como hemos visto, en el resto de diccionarios, pues es evidente que en los pasajes referidos no parece que $\pi \alpha \theta$ kós tenga ese sentido, sino otro más bien fisiológico o médico (morbosus; ỏ $\lambda$ ıoxpóvıov,

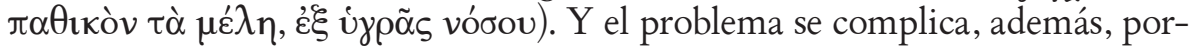
que desde hace casi tres décadas contamos también con dos testimonios del término $\pi \alpha \theta$ «ós que corroboran su significado original, es decir el conocido sentido sexual de lat. pathicus. En efecto, desde 1989 tenemos constancia del término (en la forma $\pi \alpha \theta \eta$ kós, con $\eta$ por $\mathbf{\imath}$ ) en un grafito injurioso de entre los siglos IV y VI, procedente de Afrodisias ${ }^{74}$, y desde 1999 en un famoso fragmento papiráceo editado por Parsons (P.Oxy. 66.4502, conocido como el "nuevo Nicarco") que ha conservado, entre otros, un epigrama (1. 30-37) de este poeta helenístico que presenta una novedosa interpretación burlesca y obscena del enigma de la Esfinge cuya solución sería precisamente el òvì $\pi \alpha \theta$ «ós (1. 31), es decir el hombre homosexual o pathicus, que a su condición

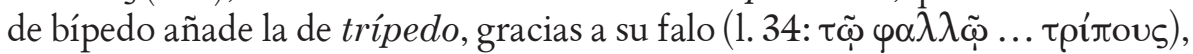
y la de cuadrúpedo, "cuando se hinca a cuatro patas con ambas manos en

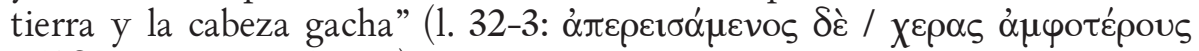

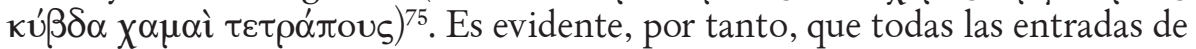
$\pi \alpha \theta \imath$ kós en nuestros diccionarios deben corregirse, no solo a la vista de estos nuevos testimonios, como ya indicaba Bain hace unos años ${ }^{76}$, sino también de los previamente conocidos del glosario latino-griego del Pseudo-Filóxeno y el poema astrológico de Camatero. Respecto a este último, en todo caso, cabe subrayar que, aunque esta vez no se trata de un término utilizado con

${ }^{73}$ Cf. Pape: "Sich leidend verhalten, der unnatürliche Unzucht mit sich treiben lässt,

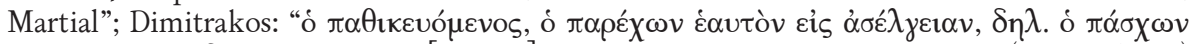

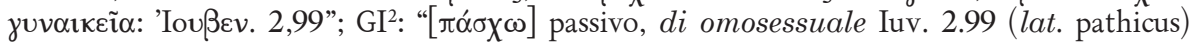
ecc.". El de Bailly es el único gran diccionario moderno que no tiene una entrada para el térmi-

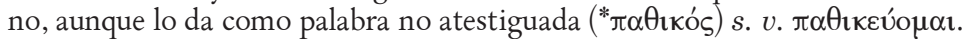

${ }^{74}$ Cf. IAphrodisias 2.218ii (= McCabe, PHI Aphrodisias 782), y vid. al respecto D. Bain, "Two submerged items of Greek sexual vocabulary from Aphrodisias", ZPE 117, 1997, 81-4, $81 \mathrm{~s}$.

${ }^{75}$ Sobre este papiro vid. ahora el trabajo recopilatorio de A.M. Morelli, "Il papiro di Nicarco (POxy LXVI 4502) e l'epigramma latino”, en L. Del Corso, F. De Vivo, A. Stramaglia, cur., Nel segno del testo. Edizioni, materiali e studi per Oronzo Pecere, Florencia 2015, 41-60, espe-

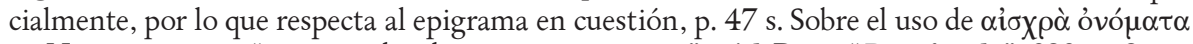
en Nicarco y otros "occasional vulgar epigram writers", vid. Bain, "Praefanda", 393, n. 9.

${ }^{76} \mathrm{Vid}$. Bain, "Some Addenda and Corrigenda", 130. 
sentido sexual en un texto de astrología, como son todos aquellos de los que nos venimos ocupando en este trabajo, sí que tiene al menos la importancia de ser un testimonio más, aunque muy tardío, de una palabra escasamente atestiguada hasta hace bien poco.

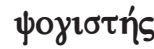

Se trata aparentemente de un nomen agentis derivado del verbo $\psi$ ơí $\zeta_{\omega}$

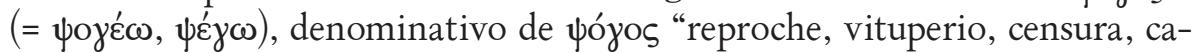
lumnia”, por lo que su sentido en principio no debería estar muy lejos del que da el LSJ (fault-finder, algo así como “criticón” o "maldiciente” en español), que es por cierto el único diccionario de griego antiguo que recoge por ahora el término ${ }^{77}$. El TLG registra esta palabra solamente en dos ocasiones, en sendos pasajes de Retorio a los que ya nos hemos referido anteriormente ${ }^{78}$, y en

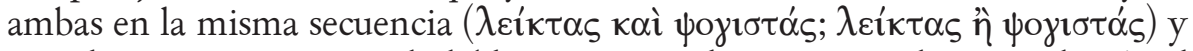
con el mismo contexto indudablemente sexual, como ya indica, por demás, el

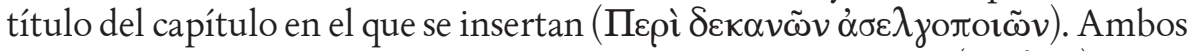
pasajes, en efecto, enumeran las conductas sexuales "lascivas" ( $\dot{\alpha} \sigma \varepsilon \lambda y \tilde{\eta})$, "des-

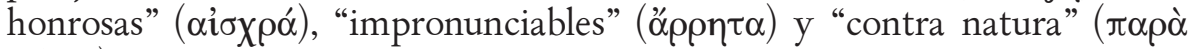

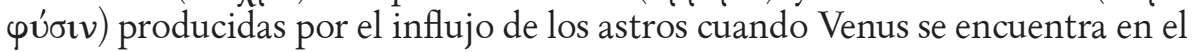
primer decano de las constelaciones de Aries y de Capricornio, especialmente el vicio depravado del sexo oral, al que se refiere con claridad, como ya vimos,

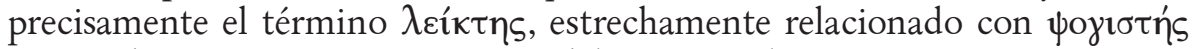
en sus dos únicas apariciones. Señalábamos también supra cómo Cumont explicaba estos dos términos (erróneamente respecto al primero, como ya demostramos, y dudosamente respecto al segundo, como veremos a continuación) indicando que se referían a fellatores et cinaedi. Pero se nos antoja

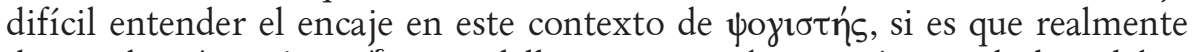

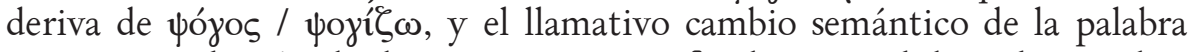
que esto implicaría, desde su supuesto significado original de "calumniador, maldiciente" al de "homosexual pasivo", que es, como sabemos, el sentido habitual de cinaedus (gr. kívaıઠos); un cambio semántico, además, para el

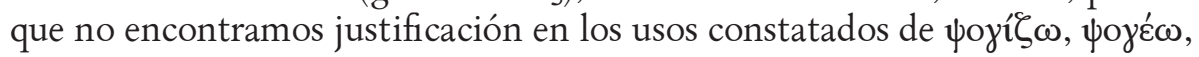

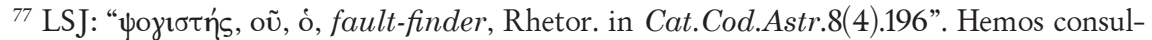
tado también infructuosamente casi todos los diccionarios de griego moderno al uso, y solo lo hemos encontrado, con el mismo sentido que da el LSJ y la indicación de que se trata de un término antiguo, en el diccionario que ofrece, sin nombre de autor (Dictionary of Greek, 2013),

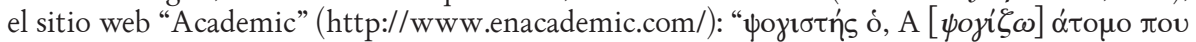

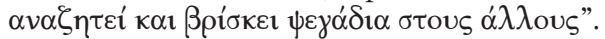

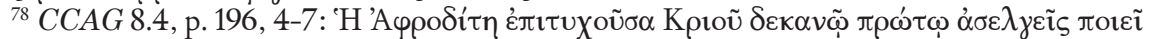

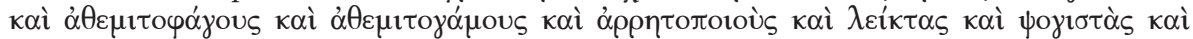

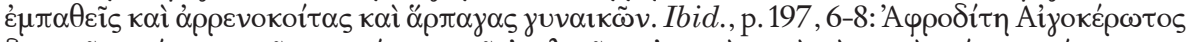

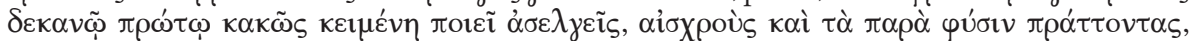

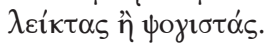


etc. ${ }^{79}$ Debemos advertir, no obstante, que en ambos pasajes de Retorio se trata de una corrección del editor a la lectura $\psi \omega \gamma \eta \sigma \tau \alpha \dot{s}$ del códice parisino (los otros manuscritos que conservan el texto omiten el final de la frase en ambos casos) ${ }^{80}$, lo cual, unido a la estrecha relación del término con el obsceno $\lambda \varepsilon i ́ k \tau \eta$ y al contexto general en el que se insertan, permite pensar que se trataría de otro término obsceno, quizá derivado de $\psi \omega \lambda \eta \eta^{\prime}$ "polla, capullo" (sensu obscaeno hispanice $)^{81}$, y sugerir la posibilidad de que estemos ante un nuevo vocablo, * $\psi \omega \lambda \imath \tau \tau \eta \dot{s}$, que paleográficamente no plantearía problemas (lambda y gamma son fácilmente confundibles en la escritura griega) y morfológicamente sería un perfecto sustantivo agente de otro verbo hipotético

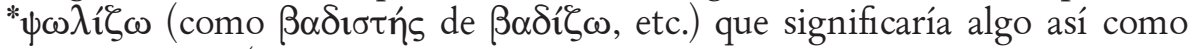
"usar la polla" (quizá específicamente para darla a mamar a un irrumator,

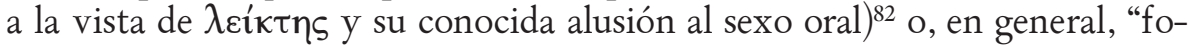
llar". En este sentido parece apuntar la frase inmediatamente siguiente al segundo pasaje de Retorio, donde leemos (CCAG 8.4, p. 197, 8-10): 'A

\footnotetext{
${ }^{79}$ Lo único que se nos ocurre pensar es que el vicio malsano de criticar de algunas personas fuera percibido en ocasiones como característico de las mujeres, como ocurría con los gritos (recuérdese, por ejemplo, el retrato de la mujer-asno de Semónides), el llanto y el lamento (plañideras) o con el chismorreo ocioso y procaz y el parloteo y la charla vulgar y picante, y que de ahí pudiera aplicarse también a los afeminados, en la idea de que los hombres parlanchines y lenguaraces tendrían escasa virilidad. Ahondar en la hipótesis de tal deslizamiento semántico,

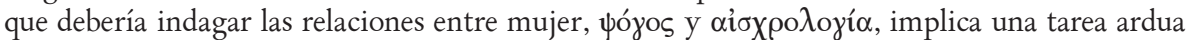
de recopilación y análisis de textos que desborda el presente trabajo y que, por tanto, dejamos aquí solamente apuntada. En todo caso, sobre las características del sociolecto femenino en la Grecia antigua puede leerse ahora con provecho el librito de J. Redondo, Para una sociología del griego. Estudio de los sociolectos de la lengua griega: literaturas clásica, helenística e imperial, Madrid 2016, especialmente pp. 17-33.

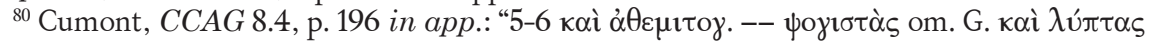

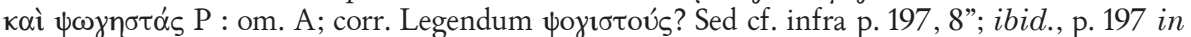

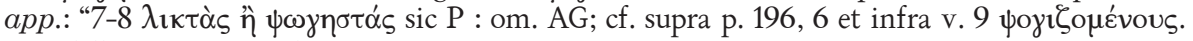
Sunt fellatores et cinaedi".

${ }^{81}$ Frente a los vocablos $\pi \varepsilon ́ o s$, forma vulgar habitual para referirse al pene en griego clásico,

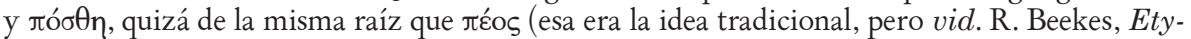

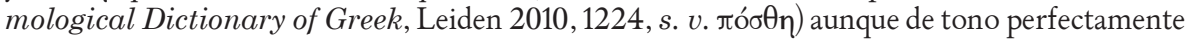
respetable y usado como término técnico en escritos médicos, la palabra $\psi \omega \lambda \lambda \eta n$ y sus derivados se refieren, al menos originalmente, al pene erecto o circuncidado y tienen por tanto un fuerte

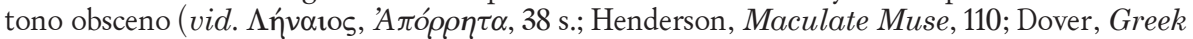
Homosexuality [cit. en n. 10], 196; Bain, "Praefanda", 410, n. 69), si bien existe algún caso en que la acepción obscena se ve atenuada para aludir metafóricamente a la pobreza e indigencia de un individuo: vid. O. Imperio, "Linguaggio delle ingiurie e linguaggio degli oracoli: Ar. Pl. 267-Eq. 964”, en G. Bastianini, W. Lapini, M. Tulli, eds., Harmonia. Scritti di filologia classica in onore di Angelo Casanova, Firenze 2012, 391-403.

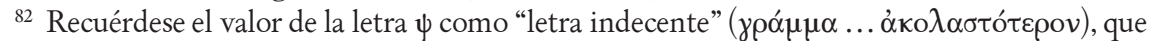
gráficamente le recuerda la vulva femenina a Euno, el pedagogo lamerón de Ausonio (Ep. 87.57), o que, formando la sílaba $\psi \omega$ ( en evocación de $\psi \omega \lambda \eta ́$, $\psi \omega \lambda$ ós “descapullado”, etc.), se utiliza como chistosa alusión obscena en un fragmento de comedia citado por Ateneo (X 454a): vid. sobre todo ello F. De Martino, "Sigle ed eufemismi alfabetici", en De Martino, Sommerstein, Studi sull'eufemismo, 99-180, en p. 172.
} 


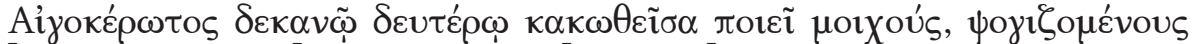

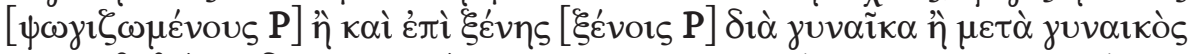

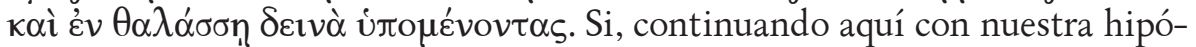

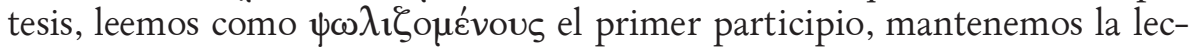

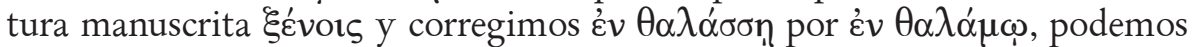
vislumbrar el sentido fuertemente obsceno de esta frase (que de hecho, salvo en el códice parisino, aparece omitida en el resto de manuscritos) $)^{83}$ y encontrar, creemos, un apoyo no pequeño a nuestra propuesta de interpretación ${ }^{84}$.

Estas, en fin, son solo algunas muestras de la riqueza de los textos astrológicos griegos respecto a vocabulario sexual y obsceno ${ }^{85}$ y del indudable valor que puede tener un estudio como el que proponemos para el conocimiento en profundidad del léxico erótico de la lengua griega.

${ }^{83}$ Cumont, CCAG 8.4, p. 197 in app.: "9-10 фoyı

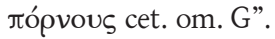

${ }^{84}$ Para ser honestos, y porque suum cuique, debemos decir que la idea de relacionar

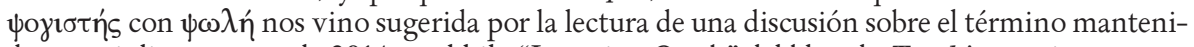
da entre julio y agosto de 2014 en el hilo "Learning Greek" del blog de Textkit, una interesante página sobre didáctica de las lenguas clásicas creada en 2001 por Jeff Tirey. Agradecemos a los intervinientes en la discusión (que puede verse en http://www.textkit.com/greek-latin-forum/ viewtopic.php? $\mathrm{f}=2 \& \mathrm{t}=61817$ ) sus interesantes ideas y jugosos comentarios, aunque nuestros intentos de registrarnos en el sitio y tener así acceso al perfil de cada uno de ellos ("Archimedes", "mwh", "daivid" y "Qimmik") han sido infructuosos.

${ }^{85}$ Pero no solo de los textos griegos, sino también de los latinos, especialmente Fírmico Materno o el Hermes Latinus, en los que encontramos numerosos casos de palabras (o significados de estas) poco o nada atestiguadas por otras vías, de sentido oscuro o tradicionalmente mal

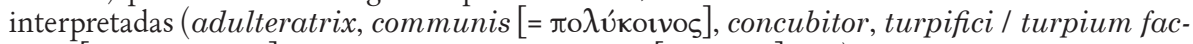
tores $[=\alpha i \sigma \times \rho \circ \pi$ oเói $]$, crissatrix, fricatrix, virago $[=\tau \rho \mathrm{\imath} \beta \alpha \dot{s}]$, etc.), en la línea de los términos que hemos visto en este trabajo. 